\title{
An integrative model of goal pursuit
}

\author{
Marina Milyavskaya \\ Carleton University
}

\author{
Kaitlyn M. Werner \\ University of Toronto
}

\begin{abstract}
There are currently a multitude of theories, models, and constructs that seek to explain the process of goal pursuit and how to maximize goal attainment. In this paper, we review existing research on the goal pursuit process and propose a model that integrates evidence from a variety of theories and perspectives. The proposed integrative model of goal pursuit explains the process of goal pursuit from inception to attainment (or abandonment) and addresses the influence of the broader social context and the dynamics that may arise when pursuing multiple goals. We also highlight how our integrative model of goal pursuit builds on specific prior theories and models of goal pursuit and self-regulation, and outline implications for future research and practice.
\end{abstract}

Keywords: goal pursuit, self-regulation, personal goals

\section{THIS MANUSCRIPT IS UNDER REVIEW - IT HAS NOT BEEN PEER-REVIEWED} AND IS SUBJECT TO CHANGE THROUGHOUT THE EDITORIAL PROCESS.

"What keeps me going is goals"

- Muhammad Ali

"A goal is not always meant to be reached; it often serves simply as something to aim at."

- Bruce Lee

Goal pursuit is ubiquitous in our everyday life. As the quotes above suggest, goals can keep us going and can provide something to aim at; they guide our actions, big and small. Indeed, goal pursuit can be considered as the cornerstone of human behaviour. It is no surprise, then, that psychologists have been interested in goal pursuit, which has been studied from multiple angles and approaches. Despite, or perhaps because of, these multiple angles, the literature on goal pursuit is fragmented. In this paper, we review and integrate different components of goal pursuit into one unified model. We define a goal as a cognitive representation of a desired end state that a person is committed to attain (Milyavskaya \& Werner, 2018; see also Elliot \& Fryer, 2008).

Correspondence concerning this manuscript should be addressed to Marina Milyavskaya, Department of Psychology, Carleton University, 1125 Colonel By Drive, Ottawa, ON, K1S 5B6, Canada. Email: marina.milyavskaya@carleton.ca

Acknowledgements: The authors thank Johanna Peetz for providing feedback on an earlier draft of the manuscript.

Funding: The preparation of this manuscript was supported by funding from the Social Sciences and Humanities Research Council (SSHRC) of Canada, including an Insight Grant awarded to MM and a Banting Postdoctoral Research Fellowship awarded to KMW.
There are currently a multitude of theories, models, and constructs that seek to explain the process of goal pursuit and how to maximize goal attainment (e.g., rubicon model of action phases, Gollwitzer, 1990; Heckhausen \& Gollwitzer, 1987; expectancy-value theory, Eccles et al., 1983; Eccles \& Wigfield, 2002; control theory, Carver \& Scheier, 1982; integrative model of self-control; Kotabe \& Hofmann, 2015; goal systems theory, Kruglanski et al., 2002). The problem with existing models, however, is twofold: (1) they tend to focus on certain aspects of goal pursuit in isolation (e.g., goal setting), while overlooking others (e.g., goal striving), and (2) they often ascribe to a particular theoretical lens, while often ignoring other, and likely complementary, theories, constructs, and models. We propose a more holistic, integrative model of goal pursuit that builds on existing models (including the rubicon model of action phases, Gollwitzer, 1990, and the cybernetic model of selfregulation, Carver \& Scheier, 1982) and incorporates evidence from a variety of theories (e.g., those mentioned above) and perspectives in psychology (e.g., social, personality, cognition, developmental, neuroscience). In this integrative model of goal pursuit (see Figure 1), we aim to explain the process of goal pursuit from inception to attainment (or abandonment), as well as address the influence of the broader social context and the dynamics that may arise when pursuing multiple goals. 


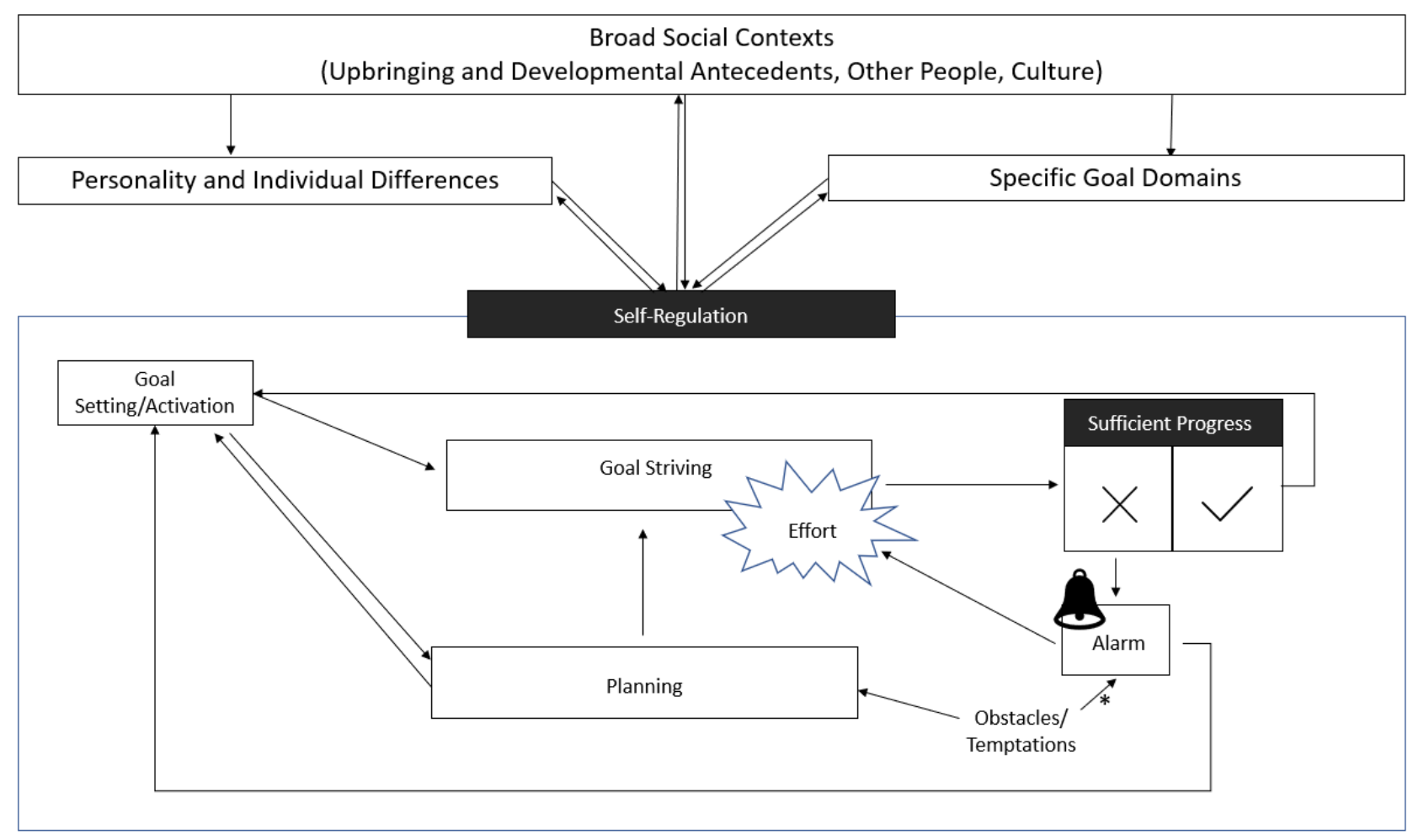

Figure 1. Integrative Model of Goal Pursuit.

Note: Although temptations/obstacles originate outside of the goal pursuit process, they can also be influenced (reduced) by planning. *Sometimes temptations/obstacles raise the alarm, but other times if they are strong they actually activate a competing goal, switching the self-regulation process to focus on another goal.

\section{Self-Regulation}

At the most basic level, we propose that goal pursuit is a feedback loop consisting of goal setting, goal striving, and progress (Carver \& Scheier, 1982). That is, people set goals that then become the reference value or standard against which behaviour is evaluated. Indeed, the process of goal pursuit is creating a discrepancy between the present and desired state (i.e., goal setting), which is then reduced through action (goal striving). In line with prior theories, we term this broad process of setting standards, acting to reduce discrepancies, and monitoring outcome as selfregulation (Inzlicht et al., 2021; Milyavskaya et al., 2019).

\section{Goal Setting and Activation}

Goal Setting. The first phase of self-regulation is deciding on what goal to pursue. This is done by considering the value of the outcome (i.e., how desirable it is), along with the expected likelihood of reaching that outcome (termed expectancy, or feasibility; Eccles et al., 1983; Eccles \& Wigfield, 2002; Lewin et al., 1944). The value of an outcome is a subjective consideration representing a calculation that involves multiple inputs, such as the incentives or objective outcomes of attaining the goal, the value of the process, and the costs involved in goal pursuit and attainment (Gollwitzer, 1990; Eccles et al., 1983). For example, if Mark is deciding whether to set the goal of getting an $\mathrm{A}$ in his math class, he might consider the longer-term benefits of getting the A for his future career aspirations, the reaction of his parents, the amount of work that would go into the process, how much he likes or dislikes the subject, and the implications of getting an A (versus not) for his selfconcept. Importantly, even the same objective outcomes likely have different values to different people (one person may value a $\$ 1,000$ bonus a lot more than someone else, which is a demonstration of utility value). Feasibility refers to the subjective 
expectation of success, which is influenced both by perceptions of self-efficacy and of task demands (Bandura 1997; Eccles \& Wigfield, 2002). In the above example, Mark might consider his previous math achievement, his beliefs about his own competence (both generally and specifically in math), as well as how difficult he expects this class to be (based on what he heard from other students, or from the expectations laid out by the teacher at the start of the year). What distinguishes a goal from a wish or fantasy is one's commitment to attaining the desired outcome (Gollwitzer, 1990; Oettingen, 1996, 1999). Commitment can be defined as the "attachment to or determination to reach a goal" (Locke, Latham, \& Erez, 1988), and is based in part on the outcome of weighing value and expectancy (Gollwitzer, 1990). Extensive research, predominantly in organizational psychology, has empirically examined these predictors of commitment, finding that both expectancy, value, and their product predict commitment (Klein et al., 1999). Based on our definition of a goal as a cognitive representation that involves commitment, we argue that a desired end-state has to be consciously endorsed to become a goal. That is, at some point a person needs to think "this is what I want to pursue". Furthermore, commitment is not a simple dichotomy where people either affirm their commitment or not (e.g., "yes, I am committed" or "no, I am not"). Rather, the amount of commitment a person has can vary, as its strength is largely determined based on relative comparisons, thus leading to shifts in goal pursuit. Commitment to a given goal can also wax and wane over time, often based on the value or presence of competing goals (e.g., Orehek et al., 2011). For example, Mark typically is committed to living a healthy lifestyle, which includes getting the recommended eight hours of sleep each night. However, when Mark has a deadline looming for an assignment, his commitment to his sleeping goal may be reduced as his commitment to finishing his assignment before the deadline increases.

Theoretical and empirical work on goal setting has predominantly focused on the properties of the goals that people set, and how these properties influence goal pursuit and attainment (for an overview, see Austin \& Vancouver, 1996). For example, goal setting theory (Locke \& Latham 1990, 2006) is built on accumulated evidence that specific, difficult goals lead to better performance than easier, abstract, or 'do your best' goals. Similarly, self-determination theory proposes that one's motivation matters, such that self-concordant goals that are in line with personal interests and values are more likely to be attained than self-discrepant goals that are alien to the self (Sheldon \& Elliott; 1998, 1999). Other theoretically relevant properties of goals include approach-avoidance motivation (Elliot, 1999), learning-performance (Elliott \& Dweck, 1988), extrinsic-intrinsic (Kasser \& Ryan, 1996), and promotion-prevention (Higgins, 1997). To date, there have been relatively few attempts at integrating these various properties, with most of this research focusing on investigating two properties or theories at a time (e.g., Kozlowski \& Bell, 2006; Seijts et al., 2001; Vaughn, 2017; Werner et al., 2018). A full discussion of these potential integrations is outside the scope of this paper.

Although goal setting and commitment is a personal endeavour, often the goals that a person pursues are first suggested to them or imposed on them by others (e.g., a supervisor, teacher, parent, spouse, peer). In these cases, however, there are still multiple options. The person can accept the goal as is, adjust it (including adjusting the difficulty or deciding to delay it), or give up on the goal altogether. If they accept the goal, the reasons for pursuing it might remain completely external, or they may internalize the goal by adding new sources of value stemming from personal interests (Grolnick et al., 1997; Ryan \& Deci, 2017). For example, a child told to clean up her room may eventually internalize this process by deriving pleasure from having a clean room, beyond the value of pleasing her parents. This process involves adding additional internal sources of value (e.g., the moral self; Kochanska, 2002) or reinterpreting the outcomes to attach additional benefits to them, thereby generating greater commitment to the goal and ultimately improving goal pursuit.

Goal Activation. Once a person decides on a goal that they will pursue, this goal, along with its associated properties, is encoded and stored in memory. A goal that is currently activated directs behaviour and is strengthened the longer it stays active. If another goal needs to be prioritized (more on how this happens later), the original goal fades into the background and can get retrieved, or activated again later. Research and theory on goal-directed cognition has examined the cognitive underpinnings of how these processes occurs (Altmann \& Trafton, 2002; Anderson et al., 2004). In our model, we include goal activation together with goal setting, as both cases (when a goal is first set/decided on, and when it is later retrieved and activated) represent how a goal becomes active in directing behaviour, leading to the other steps in the model (i.e., goal striving or planning). Furthermore, even though during goal setting a desired end-state has to be consciously endorsed to become a goal, 
subsequent activation of this goal can occur outside of awareness (Chartrand \& Bargh, 2002; Marien et al.,2012). And although during goal setting the goal is imbued with specific characteristics or properties, we argue that when a goal is subsequently activated these properties can shift somewhat. That is, a goal, when reactivated, can be appraised as more or less difficult, self-concordant, promotion oriented, etc., than when the goal was first set. For example, Mark may first perceive his goal of getting an A in math class as difficult, and want to reach it to outperform his peers (i.e., a performance goal; Elliott \& Dweck, 1998), but after a particularly engaging lesson he may reappraise the goal as easier, more interesting and personally relevant. This can occur because goals are cognitive structures (Kruglanski, 1996), and are linked to other cognitive structures that can change based on new experiences that lead to shifts in their content. That is, Mark's cognitive representation of his goal of getting an A in math class may change based on shifts in his cognitive representation of math from boring to fun, which would result in additional links between the math goal and other cognitive concepts related to fun.

\section{Goal Striving}

Once a goal is decided on, goal striving is where the person takes actions to bring themselves closer to the desired end state. This has been termed the actional phase in the rubicon model (Gollwitzer, 1990). Goal striving is a broad category that encompasses all actions that directly or indirectly move a person closer towards their goal or which the person thinks will move them towards their goal (sometimes called means or subgoals; Kruglanski et al., 2002). For example, if Mark is trying to lose weight, he might go to the gym, refuse a piece of cake offered to him by his co-worker, eat a salad for lunch, pass by a baked goods store without noticing it, purchase new workout clothes, or ask his partner to refrain from buying junk food. Note that Mark eating a salad is considered goal striving even if the salad is unhealthy, as long as Mark believes that his actions are helping him attain the goal. Additionally, these actions do not necessarily have to be performed by Mark himself- for example, if his spouse does not buy junk food, this still helps Marks' goals (more on the role of others below).

Effort. One important discussion in the literature concerns the extent to which goal striving requires conscious effort. Effort can be defined as "the mobilization of (mental or physical) resources to carry out behaviour" (Gendolla \& Wright, 2009). It is frequently considered as costly (but see Inzlicht et al., 2018 , for discussion of when effort can be considered as intrinsically valuable). Importantly, there exists a distinction between objective and subjective effort, as people are frequently unaware of the amount of effort they are exerting (Marcora, 2009; Steele, 2020). We argue that some effort is always needed for goal progress to occur, although this effort may or may not be subjectively perceived. In many cases, individuals recognize that they are exerting effort, and self-report measures of effort strongly predict making greater goal progress (Sheldon \& Elliott; 1998; Werner et al., 2016). Other research, however, argues that goal pursuit and self-regulation can unfold effortlessly or automatically (Gillebaart \& deRidder, 2015; Fujita, 2011). In such cases, the person may either be unaware of the increased effort they are exerting (e.g., when they are in a state of flow while at work; Cziksentmihalyi, 1990), or use more efficient goal-pursuit strategies such that less effort needs to be exerted (e.g., turn off distractions so that less effort is needed to focus on writing).

In the case of non-conscious goal pursuit (such as in priming studies, e.g., Chartrand \& Bargh, 1996; Papies \& Hamstra, 2010; or habits, e.g., Wood \& Neal, 2007), effort is exerted towards the goal outside of the person's awareness (i.e., they are not realizing that they are putting in more effort towards a specific goal). Other times, a person may retrospectively realize that they are mobilizing greater effort, but not the reason for it. For example, in the cases where the goal is activated outside of awareness, a person may not be aware of the reason why they are putting in the effort (e.g., Custer \& Aarts, 2007; for an overview, see Moskowtiz \& Gesundheit, 2009). Indeed, neuroscience research has shown that people automatically mobilize control and adjust their behaviour in response to neural detection of conflict (Kerns et al., 2004). In other cases, such as when a person experiences a state of flow (Cziksentmihalyi, 1990; Cziksentmihalyi \& Rathunde, 1993), a person may not feel like they are putting in effort, such that the process feels easy despite objective effort (Werner et al., 2016). Additionally, the amount of effort necessary for goal pursuit can also be reduced through habits. In habits, the behaviour may be conscious but automatic, such that (relatively) less effort is needed to accomplish the same action because the person does not need to exert willpower (Wood \& Neal, 2007; e.g., learning to drive vs. being an experienced driver - more mental effort is required in the first case, but in both cases they aware that they are 
driving). Finally, certain characteristics of the goals themselves may make goal pursuit seem more effortless (Milyavskaya et al., 2015; Werner et al., 2016); how and why this is the case requires further investigation.

\section{Sufficient Progress}

As people take actions that bring them closer to their goal, they also monitor their progress to ensure that these actions are having the desired effects. In monitoring progress, the person compares their current state to their desired state to determine if a discrepancy exists, and whether the extent of the discrepancy is diminishing at a sufficiently rapid rate (Carver \& Scheier, 1982; 1990). That is, is the discrepancy getting smaller, is that happening fast enough, and how much further does a person have to go? Such goal monitoring is included in many interventions and has been shown to have a small to medium effect on goal attainment (Harkin et al., 2016).

Even when people are not consciously monitoring their progress, they generally nevertheless receive feedback on the amount of progress that they are making. Sometimes this may occur spontaneously (e.g., someone complimenting you on the weight you lost), although frequently this is built into the goal pursuit process (e.g., receiving grades on assignments and tests, yearly reviews at work, regular check-ups at your doctor, etc.). Feedback on goal progress is also obtained through our affect. Research has shown that progress is tied to positive affect, while lack of progress results in negative affect (Carver \& Scheier, 1990). Furthermore, the rate of progress (how quickly or slowly progress is being made; termed velocity) similarly has affective consequences (Beck et al, 2017; Lawrence et al., 2002). This affective feedback has been found to be adaptive in regulating goal pursuit (Fishbach et al., 2010; Louro et al., 2007).

Independently of how the information is obtained, perceptions of sufficient progress can indicate the necessity to switch to a different goal (Louro et al., 2007), or to readjust the goal upwards (Ilies \& Judge, 2005; Wang \& Mukhopadhyay, 2012), thereby leading back to goal setting/activation. A lack of goal progress, on the other hand, leads to an alarm that signals a discrepancy between the current and desired state.

\section{Alarm}

According to the cybernetic model of selfregulation, a lack of goal progress indicates that there is a discrepancy that needs to be addressed (Carver \& Scheier, 1982). We propose that this discrepancy acts as an alarm that can get the person to reinforce their goal striving processes. Similarly, this alarm can also arise when conflict is experienced between goal pursuit and a desirable alternative (see more on this below). Although the alarm generally engenders greater effort (e.g., getting a B on a test when your goal is an A may lead you to study more), sometimes, however, when the discrepancy is great, the alarm can also lead to goal disengagement or to readjusting your goals downwards (e.g., setting a new goal of earning a $\mathrm{B}+$ instead).

At the most basic level, this alarm manifests as a physiological and neural response to errors (Hajcak \& Foti, 2008). It has also been proposed that the anterior cingulate cortex (ACC), which is the brain area responsible for monitoring for errors, also monitors for conflict (Yeung et al., 2004). Conflict detection in turn leads to greater behavioural adjustment and the activation of controlled neural processes (in the prefrontal cortex; Kerns et al., 2004). This can give rise to greater effort mobilized in the service of attaining the focal goal. Additionally, although neural processes are constantly monitoring for conflict, in many cases the conflict itself is not consciously detected. Such conflict, however, also gives rise to mixed (Berrios et al., 2015) or negative (Saunders et al., 2015) emotions, and is experienced as aversive (Elkins-Brown et al., 2016). This in turn can then enter consciousness and direct action. Indeed, negative affect has been proposed as the phenomenological indicator of the alarm being activated (Carver \& Scheier, 2000; Schmeichel \& Inzlicht, 2013). That is, when people experience that the discrepancy is large, and more importantly that the rate of discrepancy reduction over time is not satisfactory (i.e., not enough progress is made), they feel unpleasant emotions, which serves as an alarm.

In order for the alarm to be adaptive, it should, in most cases, lead to greater effort, thereby reducing the discrepancy between current progress and the goal standard. Such exertion of effort is especially needed when a person is faced with a temptation or obstacle, or something that disrupts automatic goal striving. Based on Kotabe and Hofmann's model of integrative selfcontrol (Kotabe \& Hofmann, 2015), effort is needed when a desire conflicts with a higher order goal. Similarly, when a person experiences an unexpected obstacle (e.g., the gym is closed), additional effort is needed to undertake a different action that would once 
again bring the person closer towards the goal (also referred to as means substitution, Kruglanski et al., 2002, 2015). In addition, experiencing a lack of progress towards the goal can similarly trigger the alarm. The activation of the alarm can thus provide a subsequent boost to goal striving by engendering greater effort (subjective and/or objective). Alternatively, when the discrepancy or conflict is too great, the alarm can also signal that the goal is too difficult or no longer desirable, leading the person to abandon or readjust their goal (either permanently or temporarily).

Obstacles and Temptations. A common regulatory experience that activates the alarm is the presence of obstacles, or "interfering forces that prevent people from reaching their goals" (Marguc et al., 2011, p. 883). Obstacles come in many forms - not having enough time, energy, or resources to complete a task (e.g., wanting to go for a run, but you have back to back work meetings all day), outside forces that stand in the way of one's behaviours (e.g., wanting to go for a run, but it is heavily raining outside), and/or momentary experiences of desire that conflict with one's goals (e.g., wanting to go for a run, but you are instead tempted to stay inside and watch Netflix). Research on self-regulation has paid special attention to this latter form of conflict, as these problematic desires - known as temptations - are frequently experienced in daily life (Hofmann et al., 2012). Obstacles can affect goal pursuit in a number of ways. First, perceiving possible obstacles can sound the alarm, which in turn would lead to greater effort to overcome the obstacle (i.e, selfcontrol; Hofmann et al., 2012). Similarly, anticipation of obstacles can lead a person to craft specific plans for resolving these obstacles (Duckworth et al., 2011; Duckworth et al., 2013; Oettingen et al., 2015). Alternatively, experiencing a strong temptation can sometimes lead a person to temporarily abandon the original goal and instead pursue a different goal directed at acting in line with the desire. For example, upon hearing that his friends are going out for a drink, Mark may ignore his earlier goal to study that evening and focus on getting ready to join them. Such goal switching is described in more detail in the section on multiple goal pursuit.

Identifying that a conflict exists is considered a critical step in determining whether additional effort is exerted (Myrseth \& Fishbach, 2009). For example, does Angela consider eating a cookie as an innocent one-time indulgence, or as an obstacle to her goal of being healthy? We propose that a situation that creates a conflict with the higher order goal (such as experiencing a competing desire) triggers the alarm, informing the individual that more effort is required. The conscious effort that people then put into handling the conflict between two goals (e.g., resisting temptation) is what we call self-control (Inzlicht et al., 2021). Note, however, that such conflicts may not be consciously recognized, and can be handled unconsciously through either the automatic allocation of more effort (e.g., habitual behaviour) or a decision in favour of the tempting alternative. Recent computational models of self-control identify that conscious self-control is called upon when two options have similar value, and a decision requires conscious evaluation (Berkman et al., 2017).

Goal Adjustment and Resetting. When the alarm is activated, and people experience goal-related negative affect, an alternate way to reduce the discrepancy between the goal and the current state is to change the goal (see Wang \& Mukhopadhyay, 2012, for a detailed model of goal readjustment). Indeed, when a goal seems too difficult, instead of putting in more effort people will sometimes withhold all effort (Gendolla \& Richter, 2010; c.f. Stanek \& Richter, 2021) and subsequently disengage from the goal (e.g., a student quitting school). This is often preceded by an action crisis, where a person will reconsider whether they truly want to be pursuing that goal (Brandstatter \& Herman, 2016; Brandstatter et al., 2013). During this time, the person may start to devalue the focal goal (e.g., Lisa might begin to refute some of the health benefits of regular exercise), so that it feels less desirable (Ghassemi et al., 2017). In the cases of unattainable goals, such disengagement is adaptive (e.g., Wrosch, Scheier, Carver, \& Schulz, 2003; Wrosch, Scheier, Miller, et al., 2003). Other times, people will reduce their goal but without disengaging completely from the domain (e.g., a student changing their grade goal from a $\mathrm{B}+$ to a $\mathrm{B}-$ ).

Alternatively, positive progress can also lead to changes in the goal itself. Positive affect experienced as a consequence of positive feedback, signaling a reduction in the discrepancy between the current state and the goal, has been shown to lead to more difficult subsequent goals (Ilies \& Judge, 2005). Indeed, positive progress can impact perceptions of feasibility, which can lead people to readjust their goal upwards (Tolli \& Schmidt, 2008). Additionally, if sufficient progress has been made, or if a goal is completely attained, people can then shift their focus to a different goal. 


\section{Planning}

Although the basic self-regulatory feedback loop consists of goal setting, goal striving, and monitoring goal progress, the pursuit of many conscious goals includes an additional step of planning how to pursue the goal. This can be done by breaking down a broader goal into smaller more concrete steps, which can also be considered as setting new smaller goals (represented by the arrow leading from planning to goal setting). Planning can also include anticipating (and avoiding) potential obstacles (Duckworth et al., 2011; Oettingen \& Gollwitzer, 2010) and specifying the specific contexts (times, places) where actions needed to attain the goal will be performed. Such specific if-then plans are termed implementation intentions (Gollwitzer, 1999). They have been extensively studied, mostly in lab paradigms, and are associated with greater goal progress (Gollwitzer \& Sheeran, 2006; Toli, Webb, \& Hardy, 2016; McWilliams, Bellhouse, Yorke, Lloyd, \& Armitage, 2019). However, given that implementation intentions are typically studied in experimental or intervention-style paradigms (see Gollwitzer \& Sheeran, 2006), it is unclear how often people spontaneously make concrete plans for their goals.

Indeed, despite being a seemingly simple technique, people seem to struggle with developing effective plans for pursuing their goals. In one study, $52 \%$ of participants reported that they did not have implementation intentions for their health goals, while only $26 \%$ reported having more concrete plans (Milyavskaya \& Nadolny, 2018); another set of studies, looking at idiosyncratic personal goals, found that respondents reported making plans for approximately $60-70 \%$ of goals (Werner et al., 2020). Also within the health domain, randomized control trials found that implementation intentions had no effect on physical activity (de Vet et al., 2009) or weight-loss (Knauper et al., 2020). In the former, this likely occurred because a substantial portion of participants (over 30\%) did not form specific enough or viable plans (de Vet et al., 2011). Altogether, research on planning shows that plans can be effective if formulated correctly, but that this is not always done frequently enough.

\section{Broader Social Contexts}

Above we described the goal pursuit cycle that comprises self-regulation. Much of the research on goals typically centers on the individual in the context of goal pursuit, including a focus on the goals that a person sets for themselves, the means by which they strive for these goals, and various internal processes like their perceived sense of agency, efficacy, commitment, etc. However, goals are not pursued in a vacuum. Although there are times when we can be proactive and set goals for ourselves, other times we are mere observers and absorb the goals around us (Bandura, 1969; McAdams, 2013). This may occur through observational learning where a person adopts a goal that they learned from their environment (e.g., Bandura, 1969; 2018) or when goals are promoted directly by other people (e.g., Carr \& Weigand, 2001; Duriez, Soenens, \& Vansteenkiste, 2008; Wouters et al., 2014). A broader social context directly influences and interacts with every aspect of the self-regulation process, from the types of goals that people set for themselves, to the obstacles that they experience and the effectiveness of goal striving. This broader social context includes ones' upbringing, culture, and others social actors in a person's environment. Additionally, individual differences (i.e., personality) can play a role in the goal pursuit process and can in turn be influenced by the broader social environment. Finally, goals are typically set in specific areas of one's life (i.e., a person can distinguish between work, school, and health goals), and the role of these specific contexts needs to be taken int account. Here we provide a (necessarily) brief discussion of how these are likely to influence self-regulation.

\section{Upbringing and Developmental Antecedents}

Parents are often considered the primary socializing agents, which allows them to have the greatest initial impact on goal development (Collins et al., 2000; Grusec \& Davidov, 2010). Indeed, thousands of papers have examined how parenting style affects goal pursuit, self-regulation, and achievement more broadly (for reviews, see Karreman et al., 2006; Spera, 2005). Generally, this research finds that an authoritative style characterized by the provision of autonomy support and structure are especially effective (Larzelere et al., 2013). This is found in most contexts (e.g., school, sports, health; Joussemet et al., 2005), and across a variety of ages ranging from toddlers to young adults (e.g., Laurin \& Joussemet, 2017; Soenens et al., 2007; Vasquez et al., 2016). Additionally, there is now a burgeoning literature on parenting interventions designed to aid parents to provide a supportive environment for their children (Joussemet et al., 2014; 2018).

Next to parents, schools play a critical socializing role; indeed, much of the research on goal pursuit is 
conducted in an educational context (Covington, 2000; Meece et al., 2003; Ryan \& Deci, 2020). This research again finds that autonomy support and structure improves self-regulation and goal pursuit, and can lead to the development of skills that can bolster future goal pursuit (Niemiec \& Ryan, 2009). For example, students who were given the opportunity to set their own goals (vs. receiving goals imposed by the teacher) had better goal-setting ability over time (Hannafin, 1981). As children grow older and their social sphere expands, additional close others start to influence thoughts, actions, behaviours, and goals, including peers (Keegan, Spray, Harwood, Lavallee, 2010), friends (Powers, Koestner, \& Gorin, 2008), teachers (Hannafin, 1981), coaches (Keegan et al., 2010), and role models (Lockwood, Jordan, \& Kunda, 2002).

\section{Other People}

As can be seen in our discussion of developmental antecedents above, a crucial contributor to goal pursuit, which becomes increasingly important and diverse over time, is other people. Indeed, transactive goal dynamics theory has recently proposed that goal pursuit is inherently interdependent, and should be studied as such (Fitzsimons et al., 2015). Research has examined the role of close others in every step of the selfregulation process. Other people influence the goals we set, either directly (a boss telling you a target to meet) or indirectly (I want to learn to cook because I think it will please my partner), and which goals we focus on at any given time (seeing my buff friend might make my own exercise goal more salient; Aarts et al., 2004). Others also influence how we pursue our goals both by providing support and by being instrumental in goal pursuit (Fitzsimons et al., 2015; Vowels \& Carnelley, 2020). The presence of other people can also keep us from giving in temptations (Hofmann et al., 2012), give us license to indulge (Dominick, 2020; Hofmann et al., 2012), or push us to outperform possible competitors (Huang et al., 2019) .

Relationships can be distinguished between vertical relationships (with people in a position of authority, such as parent, teacher, coach, or employer) and horizontal relationships (with friends and romantic partners). At first glance it may seem that others in a position of power have more influence on selfregulation, as they frequently dictate the content of goals, as well as shape the process of goal pursuit (e.g., by providing resources). Research, however, has highlighted the importance of horizontal others, specifically relationship partners and friends, in providing support for goal pursuit (Gore, 2006; Koestner et al., 2012; although note that power dynamics impact goal pursuit even in relatively more horizontal relationships; Laurin et al., 2016). Such support can be provided in many different ways support has been classified as emotional, informational, appraisal, or instrumental (Tardy, 1985), as visible versus invisible (Girme, Overall, \& Simpson, 2013), and autonomy-supportive versus directive (Koestner et al., 2012). Research has examined which type of support is more beneficial, finding, for example, that invisible support leads to more goal attainment than visible support (Girme et al., 2013), and autonomy support is better than directive support (Koestner et al., 2012). Importantly, recent research has examined not only whether different types of support lead to better goal attainment, but also the process, showing, for example, that autonomy support is related to greater goal internalization and persistence (Koestner et al., 2015).

Most of the research thus seems to examine how close others impact goal setting and adjustment (e.g., Gere \& Impett, 2018); relatively less research has focused on the other parts of the goal pursuit process (goal striving, planning, the alarm phase). It is likely, however, that the effort needed for goal striving can also be outsourced to others (e.g., partner cooks healthy meals; paying someone to do your housework). Such outsourcing is generally found to support goal pursuit, although it has only been examined in the context of romantic partners (Briskin et al., 2019; Cappuzzello \& Gere, 2018). Likewise, others can help you monitor your progress; indeed, research finds that monitoring is most effective when the results are reported to others or made public (Harkin et al., 2016), such that the alarm appears more likely to activate (i.e., be more sensitive) when others may become aware of our failures. And recent research finds that surrounding yourself with supportive others is a self-regulatory strategy that distinguishes successful from unsuccessful selfregulators (vanDellen et al., 2015; Nielsen \& Bauer, 2019). In sum, it is clear that other people play an integral role in self-regulation and goal pursuit; future reviews can begin to systematically examine how they do so across the different components of the goal pursuit process outlined in our model.

\section{Culture}

Another aspect that likely influences selfregulation, but is (relatively) less studied, is culture. Although very few papers examine individuals' goals 
across cultures, culture likely plays a role in all aspects of the self-regulation process. With regards to goalsetting, culture influences both the desirability and feasibility of possible goals (Oettingen et al., 2008), leading to differences in goals being pursued. For example, research has shown that people in individualist cultures are more likely to pursue goals that reflect the person's own interest and desires, whilst those in collectivist cultures are more likely to pursue more communal goals (Triandis, 1995). Others, however have not found differences (at least between Asian and European Americans; Oishi \& Diener, 2001), although pursuing interdependent goals led to greater well-being among Asian American participants. Examining a different aspect of goals, researchers found cultural differences (across the United States, Taiwan, South Korea, and China) in the quality of motivation (intrinsic, identified, and introjected; Sheldon et al., 2004). Even though these studies did not examine the process of goal pursuit, it may be that culture also influences how people pursue both independent and interdependent goals. Indeed, one study found differences in reported effort and social support for personal important goals among American and Japanese participants (with American participants reporting higher levels of both; Gore et al., 2009). Although there is research on how self-regulation develops in different cultures, there is still much to be learned about how culture affects goal pursuit and the pathways proposed in the current model.

\section{Personality and Individual Differences}

Extensive research has examined how personality and traits relate to specific aspects of goal pursuit, including the broad types of goals that are pursued (Roberts \& Robins, 2000), appraisals of personal goals (Little, Lecci, \& Watkinson, 1992; Dietrich et al., 2013), as well as planning and striving (Freitas et al., 2002; Powers et al., 2011). For example, conscientiousness has been linked to setting goals that have greater personal meaning, greater effort, and more progress (Little et al., 1992; Judge \& Illies, 2002; Corker et al., 2012). Similarly, research links trait selfcontrol to broad life outcomes that are thought to encompass successful pursuit of personal goals (De Ridder et al., 2012), as well as to fewer experiences of temptations (Hofmann et al., 2012), and better strategies and habits (Adriaanse et al., 2014; Galla \& Duckworth, 2015), resulting in more effortless goal pursuit. Many other individual differences, including perfectionism (Powers et al., 2011), pride (Carver et al.,
2010), inspiration (Milyavskaya et al., 2012), mindfulness (Smyth et al., 2020), optimism (Monzani et al., 2015), procrastination (Grund \& Fries, 2018), power (Guinote, 2007), assessment and locomotion (Kruglanski et al., 2009), have been implicated in the process of goal pursuit. To review all these links is beyond the scope of this paper. Note however, that surprisingly few studies have examined the effects of these personality traits on actual goal attainment in personal goals over time. Additionally, most of this research is conducted from different theoretical or research perspectives, with little cohesion. Future work is needed to summarize and organize existing literature on the role of traits in goal pursuit, providing a unifying theoretical framework to this broad and diverse area of research.

One set of individual differences that has been examined more systematically is age and life stage (e.g., Brandtstädter \& Rothermund, 2002). Here, it is proposed that individuals change the focus of their goal pursuit as a function of age-appropriate developmental tasks (i.e., finishing school, starting a family, starting a career, etc.; Nurmi, 1992), taking into account the constraints inherent in aging. Some goals (e.g., having biological children) become less attainable with age, requiring individuals to adjust their goals (Brandtstädter \& Rothermund, 2002; Wrosh, Scheier, Carver et al., 2003). The extent to which they are able to do so influences both goal pursuit and well-being (Wrosh, Scheier, Miller et al., 2003). Additionally, research finds that older individuals are often more successful in their goal pursuit because they set goals that are more in line with personal interests and intrinsic values (Sheldon \& Kasser, 2001) and are mutually facilitative (Riediger et al., 2005). In sum, one common way that age affects self-regulation by influencing goal setting and resetting, as well as dictating some of the (age-related) obstacles that people encounter during goal pursuit (see Geldhof et al., 2010, for a broader discussion of self-regulation across the lifespan).

\section{Specific Goal Domains}

The context in which a goal is embedded also plays a large part in both the goals that are set and how the goals are pursued. For example, research has shown that people set more autonomous goals in domains where the psychological needs for autonomy, competence, and relatedness are satisfied (Milyavskaya et al., 2014). Additionally, people generally set less autonomous goals in certain contexts such as school or 
work (compared to relationship and friendship goals; Sheldon \& Elliot, 2000). Similarly, research on selfregulation shows that self-control is differentially associated with self-regulatory success in different domains (De Ridder et al. 2012). Indeed, research shows that $60-95 \%$ of the variation in most goal characteristics, including goal attainment, is across domains (Holding et al., 2017; Milyavskaya et al., 2015; Nurmi et al, 2009; Werner et al., 2016), although some specific aspects of goals, such as meaning and inspiration, have greater between-person variability (Milyavskaya et al., 2012; Thomas \& Schnitker, 2017). Despite large variability, particularly in goal attainment, very little research has directly compared the process of goal pursuit across specific domain types, or tried to understand why any differences may exist. For example, does goal pursuit unfold similarly or differently for work goals as compared to relational goals? We propose that the process of goal pursuit would be the same across domains, and that it is the features of the specific goal domains that would influence that process, rather than the content of the domain. For example, school goals are typically different than leisure goals because of the extrinsic nature of school; if school was more intrinsic, then school goals would be more similar to leisure goals. Of course, not all goals set in a given domain are expected to be the same; we merely suggest that certain aspects of the domain in which the goal is set and pursued can influence self-regulation.

\section{Feedback Mechanisms - Self-Regulation Processes Influence Broader Contexts}

In addition to the various effects of contextual constraints and affordances as well as personality on goal pursuit, it is also possible to consider how goal pursuit feeds back to shape these broader constructs. For example, McCabe and Fleeson (2016) showed that goals influence the manifestation of traits at any given moment, and explain both between and within-person variance in trait-concordant behaviours. Indeed, they argue that goals and goal pursuit explain why people appear to possess certain traits, suggesting a reciprocal influence between goals and traits. Self-perception theory, which postulates that people infer their attitudes from observing their own behaviours (Bem, 1972; Fazio, 1987), also explains how goal pursuit can feed back into personality- as a function of successfully pursuing certain types of goals, a person might internalize these goals (e.g., I am jogging every day, therefore I must be a health-conscious person), which in turn can lead to setting other congruent goals (e.g., I will start eating more vegetables).

In addition to potentially shaping individual differences, how we pursue our goals influences other people's responses and interactions with us. For example, research finds that how we pursue goals can influence how we are perceived by our peers (Wentzel, 1994), and the reactions children elicit from their parents (Zhang et al., 2011). Our goals can also impact our relationships, including our partner's perception of relationship satisfaction and their well-being (e.g., Carbonneau \& Milyavskaya, 2017; Gere \& Impett, 2018). Goals are an integral part of the dynamic between a person and their environment, such that decisions regarding which goal to pursue or abandon (e.g., do I complete a masters degree, or go into the workforce?) and how to pursue them (do I join a gym or go to karate classes to get fit) shapes the environment we find ourselves in. In the course of pursuing our goals, we may seek out specific contexts and situations, or specific close others who may be more likely to assist goal pursuit (vanDellen et al., 2015). Future research can pay particularly close attention to these feedback loops to elaborate a cohesive theoretical understanding of how goal pursuit impacts these broader contexts.

\section{Multiple Goals}

So far, we have predominantly discussed how the goal pursuit process unfolds for a single goal. However, in everyday life, people often have to navigate the pursuit of multiple goals at the same time (e.g., having the goal to eat healthy, to do well in school, to be an attentive and loving partner; see Kung \& Scholer, 2020, for recent review). This includes goals that directly compete with one another (e.g., wanting to eat healthy vs. enjoying a piece of cake), hierarchically nested goals at different levels of abstraction (e.g., exercising is a goal in and of itself but also is a mean to attain a broader goal of being healthy), complementary goals (at the same level of abstraction that both serve the same broader goal; e.g., reading a paper and conducting data analyses as both helping my broader goal of being productive at work) and goals that compete for the same resources but on their own do not necessarily conflict (e.g., going to the gym and getting 8 hours of sleep are two goals that only conflict insofar as I have a limited time during my day). Although there are different models outlining how goals are structured and organized (see Kung \& Scholer, 2020 for an overview), the most prominent model is goal systems theory 
(Kruglanski et al., 2002, 2015). According to goal systems theory, goals are represented by a cognitive network comprised of interconnected goals (i.e., representations of desired end states), subgoals (intermediate goals that nevertheless lead to the attainment of broader goals), and means (i.e., behaviours that can lead to goal attainment).

Given that some goals can be enacted in the service of other broader goals, we argue that the self-regulation loop can occur in parallel for multiple goals at different levels of abstraction, such that the goal striving stage for one goal can encompass a full self-regulation loop of a subgoal. For example, to pursue a goal of doing well in school, a student could set a goal of studying for the exam, work on that goal, test their own knowledge, and fit in a late-night cramming session if they do not feel ready the night before the exam (i.e., the alarm signaled that progress was lagging). In this way, the higher order (more abstract) goal can operate at the same time as the lower order (more concrete) goal, with the concrete goal operating at a much narrower time frame.

Goal systems theory also suggests that sometimes multiple goals can be pursued simultaneously by engaging in behaviours that help multiple goals (termed multifinal means, Kruglanski et al., 2002; or concurrent goal pursuit, Orehek \& Vazeou-Nieuwenhuis, 2013). Concurrent goal pursuit may, however, represent means that are not optimal for either of the goals (but that can nevertheless advance both; Kopetz et al., 2011). Similarly, pursuing more than one goal at the same time may also divide cognitive resources (Koch et al., 2018). Other research on personal goal pursuit has found that goal congruence or facilitation - how multiple goals are perceived to help each other - is not the inverse of goal conflict, but is instead a distinct construct (Riediger \& Freund, 2004). Research finds positive effects of goal facilitation on goal pursuit and progress (Presseau et al., 2013; Riediger \& Freund, 2004), pointing to the potential benefits of finding compatible goals that help each other or can be pursued through the same means.

For goals that compete (either directly or because of competing resources), other processes take place that dictate which goal is activated and pursued at a given moment. Note that such shifts in which goal is focal can happen very rapidly, and are even sometimes considered as multitasking (when a person switches back and forth from one goal to another so rapidly that it seems as if they are doing both simultaneously; Koch et al., 2018). Indeed, most research on the pursuit of multiple goals has focused on how people prioritize their many pursuits (Ballard et al., 2016, 2018; Louro et al., 2007; Orehek \& Vazeou-Nieuwenhuis, 2013; Neal et al., 2017; Shah, 2005; Thurmer et al., 2020). Formal models have been proposed to address this issue (Ballard et al., 2016; for a review see Neal et al., 2017). Generally, goals that are more urgent or pressing will take precedence over goals that do not have such restrictions (Ballard et al., 2018). For example, needing to finish an assignment before class tomorrow would become more salient (and thus be more likely to be enacted upon) than going out on a date night with your partner (a behaviour that can in theory be enacted upon at any time). Indeed, both individual and environmental constraints influence which goal will be prioritized (see Neal et al., 2017, for a review). The most prevalent constraints include time (i.e., having a specific timeframe to achieve the goal or not), energy (i.e., the amount of effort a person can realistically invest in pursuing the goal at a given time), and abilities/resources (i.e., having the right skills, money, etc. to pursue a focal goal).

When goals are pursued sequentially, people prioritize a focal goal by dedicating resources to goal striving. Research finds that some of this prioritization happens through goal shielding, which automatically orients a person toward the focal goal of interest while simultaneously blocking out or inhibiting all other competing goals (Goschke \& Dreisbach, 2008; Shah et al., 2002; Shah, 2005). In such cases, people may experience fewer competing temptations, which is related to more successful goal pursuit (Milyavskaya \& Inzlicht, 2017). Similarly, some research has found that the activation of competing goals or temptations may even make a focal goal stronger (Fishbach et al., 2003), which further serves to protect the focal goal from distractions.

Although some research has examined how people switch to a new goal once the focal goal is complete or attained (i.e., the Zeigarnick effect; Forster et al., 2005), more frequently one goal is not fully complete when a new one is active. Furthermore, some goals are maintenance goals that can never be attained, but on which progress must be vigilantly monitored to avoid straying from the goal (Brodscholl et al., 2007). The decision to switch to a different goal can nevertheless be impacted by perceptions of progress and proximity to goal attainment or desired goal state for the focal goal (Louro et al., 2007; Thurmer et al., 2020). In our model, this is seen in the pathways from goal progress, which can lead back to goal setting/activation (when sufficient progress is made on one goal), or to the alarm (when the progress is insufficient), which in turn can 
lead to effort intensification, or to disengagement and prioritization of another goal (if the original goal is no longer feasible). Additionally, switching to another goal can occur due to external or environmental constraints (e.g., a calendar reminder signaling it is time to pick up my children from school temporarily deactivates my working goal and switches to my parenting goal).

In sum, our model addresses the pursuit of multiple goals by proposing that: (1) Self-regulatory 'loops' can be nested within each other, such that goals at different level of abstraction can be pursued simultaneously. (2) At the level of the behaviours (a.k.a. lower level-goals, or means, using the terminology from goal systems theory) only one goal is activated at a time (i.e., the focal goal), with mechanisms in place to protect goal striving. (3) This lower-level goal could be helping more than one higher-level goal, which would then mean that those superordinate goals are pursued concurrently. (4) Goal switching occurs when (a) sufficient progress has been made towards the focal goal; (b) the goal is no longer feasible (c) something else in the environment (including obstacles or temptations) activate a competing goal that takes over and becomes the focal goal.

\section{Integrating Existing Models of Goal Pursuit}

One of the main aims of the proposed integrative model of goal pursuit is to build on prior models of goal pursuit and self-regulation and create one common model that can provide a framework to organize existing and future research. Below, we outline other commonly used models of goal pursuit and selfregulation, and expand on how our model builds on them, or how they can fit or are different from the proposed model.

\section{Cybernetic Model of Self-Regulation (Carver \& Scheier, 1982, 2001)}

The cybernetic model of self-regulation initially proposed by Carver and Scheier (1982) is at the core of our model. Their model is based on earlier models of cybernetic control (Powers, 1973; Miller et al., 1960), which postulate the existence of a discrepancyreducing feedback loop. In the self-regulation model, it was proposed that a person would track the discrepancy between their current state and their goal; if a discrepancy is detected, they would act to reduce the discrepancy (goal striving in our model), and then monitor progress such that insufficient progress (a continued discrepancy) would lead to additional actions. In our integrative model of goal pursuit, we added the alarm as a mediator of noticing a lack of progress and enhanced effort.

The cybernetic model of self-regulation was later refined to include a parallel affect loop that tracks discrepancy, such that the rate at which the discrepancy is reduced (as compared with some standard for discrepancy reduction given current circumstances) will lead to differently valenced affect (Carver \& Scheier, 2000, 2001; Carver, 2015). That is, when a person is making what they perceive is sufficient progress, they will feel good; otherwise, they will feel bad. In the integrative model of goal pursuit, affect is largely ignored, but could represent the mechanism by which some of the constructs lead to one another. For example, making sufficient progress on a goal can lead to positive affect which in turn sometimes leads to switching the focal goal (i.e., coasting; Louro et al., 2007). Additionally, the alarm is thought to be manifested as negative affect.

\section{Rubicon Model (Gollwitzer, 1990)}

The rubicon model of action phases (Gollwitzer, 1990) was the first to go beyond the distinction between goal setting and goal striving by describing goal pursuit as a sequential process that included four phases: predecisional (deliberating), preactional (planning), actional (acting), and post-actional (evaluating). Similarly, Little (1983) proposed inception, planning, action, and termination as four stages through which the pursuit of personal projects unfolds. Our model also includes those phases, with the post-actional phase represented by the arrow between progress and goal setting (where a person will evaluate their progress before adjusting or resetting a goal). One key difference between our integrative model of goal pursuit and the rubicon model involves the role of planning. According to Gollwitzer, planning is an integral part of the goal pursuit process, and occurs immediately once the decision to pursue a goal is made (Gollwitzer, 1990). However, given that some goals can be pursued automatically and habitually (Neal \& Wood, 2007), we argue that in some cases, goal activation can lead directly to goal striving, bypassing the planning process altogether. Indeed, some research finds that people frequently report not having concrete plans for attaining their goals (Milyavskaya \& Nadolny, 2018).

Goal Setting Theory (Locke \& Latham, 1990, 2002) 
A large literature on goal pursuit has developed within industrial-organizational psychology, stemming from goal setting theory (Locke \& Latham, 1990, 2002). Goal setting theory has predominantly examined the role of setting specific, difficult goals on goal pursuit, showing that such goals lead to greater progress than vague, easy goals (or than rejoinders to 'do your best'; for a review, see Locke \& Latham, 2002). Most of the evidence gathered within the framework of goal setting theory could be organized in our model under the path between goal setting and goal striving. Additionally, certain moderators, such as selfefficacy, would fall into the broader contextual influences on self-regulation (i.e., self-efficacy can be considered a personality or domain-specific property, which then influences the path between goal setting and goal striving, or between goal striving and progress). Finally, the role of feedback, which according to goal setting theory is used to adjust the level of future goals (Ilies \& Judge, 2005; Locke \& Latham, 2002), is acknowledged in our paper in the feedback loop from progress to goal setting. Seminal findings from goal setting theory, such that specific, hard goals lead to greater effort and more progress (for a meta-analysis, see Epton et al., 2017), thus fit well within our integrative model of goal pursuit.

\section{Self-Determination Theory (Deci \& Ryan, 2000; Ryan \& Deci, 2017)}

Self-determination theory is a broad theory of human motivation (Deci \& Ryan, 2000). Research using this theory has focused on the influences of the broader context on how goals are set and pursued, and how the type of motivation influences behavior and goal pursuit (Ryan \& Deci, 2017). Findings from SDT can thus readily be incorporated into our framework - for example, the role of others in creating autonomy-supportive contexts that facilitate goal pursuit, and differences across domains that give rise to different types of goals are all included in the broader contextual influences described in our integrative model of goal pursuit. Using the framework of selfdetermination theory, research on goal selfconcordance has also examined why goals that are relatively more autonomous (also termed selfconcordant or want-to) are more likely to be attained, with research showing that such goals lead to improved goal striving with greater effort
(Sheldon \& Elliot, 1999), reduced experiences of obstacles (Milyavskaya et al., 2015), and more progress (Koestner et al., 2008).

\section{Integrative Self-Control Theory (Kotabe \& Hofmann, 2015)}

Focusing specifically on self-control, Kotabe and Hoffman (2015) proposed a model that integrates multiple components of self-control that ultimately explain when a person successfully exercises selfcontrol versus gives into a temptation. In our integrative model of goal pursuit, such self-control, to the extent that it leads to behavioural enactment, would fit under goal striving. The experience of conflict that, in their model, activates the exertion cluster is what we refer to as the alarm. Indeed, their model makes concrete predictions for when a temptation would lead to more effort (i.e. self-control), and when it would lead to shift to pursuing a goal congruent with the desire (i.e., desire enactment). So while their model makes much more fine-grained predictions about in-themoment self-regulation, these can be used to better understand the effect of temptations on goal striving or readjustment/temporal deactivation. Finally, properties of the higher order goal, as well as control motivation, figure prominently in their model; these are considered in our model under the goal setting label.

\section{Goal Systems Theory (Kruglanski et al., 2002, 2015)}

As described in the multiple goals section (above), goal systems theory proposes that goals are mentally represented as hierarchical networks and describes likely structural patterns (and their consequences) of these networks. Goal systems theory relates to our model insofar as it can explain the pursuit of multiple goals at different levels of abstraction, as well as how the pursuit of one goal affects pursuit of other goals. For example, our model proposes that planning for one goal can in turn lead to the setting of smaller subgoals or means. In line with the idea of counterfinal means (i.e., a means to one goal that is detrimental to another goal ), we propose that the alarm can sometimes activate alternate goals (i.e., going to a restaurant with a friend is a means that undermines my goal of saving money, which may trigger the alarm, but if I also have the goal of being social, I may shift my focus to that goal). Our model is currently silent on whether people actually use goal striving means that can aid multiple goals simultaneously (despite findings that people prefer such means in laboratory studies; Kopetz et al., 
2011). Future research can examine whether this and other principles of systems theory demonstrated in lab studies (e.g., Chun et al., 2011; Kopetz et al., 2011; Zhang et al., 2007) occur in the context of broader goal pursuit in daily life.

\section{Identity Value Model (Berkman et al., 2017)}

A recent model of self-regulation paints self-control as a decision-making process, where the value of each alternate option is dynamically computed until one of the options reaches a threshold required for that option to be enacted (Berkman et al., 2017). This model also proposes that identity provides an important source of subjective value, leading people to weigh identityrelevant goals and behaviours more heavily than nonidentity relevant ones. Fitting with our model of goal pursuit, we believe that the identity-value model can be used to explain when activation of the alarm would lead to intensifying effort, and when it would lead to disengaging and switching to alternate goal. Specifically, the valuation of the alternate options are likely driven by the processes proposed in the identityvalue model, and would heavily depend on the relation of each option to identity. Which goals are prioritized, and when, may also be guided by such calculations. It may also be a way in which personality or other individual differences guide self-regulation, since these differences will provide different sources of identity, guiding value computations. For example, a person high on agreeableness may choose to accompany a friend to a party because he views 'being helpful' as part of his identity, while someone high on conscientiousness may choose to stay home and study because school performance is important for her identity.

\section{Theories of Goal Pursuit as Levels of Personality}

Multiple theoretical perspectives consider the properties of goals that a person pursues as an individual difference, and a level of personality (e.g., Little, 1983; Karoly, 1999; McAdams, 1996). Most of these perspectives consider constructs that are very similar to goals, such as personal projects (Little, 1983), personal strivings (Emmons, 1986), and current concerns (Klinger \& Cox, 2004). These perspectives propose that goals/projects/concerns are contextualized manifestations of personality (McAdams, 1996), and represent an adaptation that "reflect the enduring psychological core of the individual" (McCrae \& Costa, 1999, pg. 144). For example, McAdams argues that 'characteristic adaptations', which include goals, values, and strivings among other motivational and socio-cognitive adaptations, are critical component for understanding the whole person (McAdams \& Pals, 2006). Goals have similarly been described as "building blocks of personality" (Freund \& Riediger, 2006). Our proposed model recognizes this approach to viewing goals as an aspect of personality by explicitly recognizing that self-regulation (including goal setting and goal pursuit) are affected both by personality and by broader social contexts and domains, thereby representing a contextualized, idiosyncratic manifestation of individual differences (Little, 2020).

\section{Implications for Future Research and Practice}

The present paper outlined an integrative model of goal pursuit, incorporating a wide variety of existing theories and research findings. Prior research on selfregulation and goal pursuit has often been scattered, drawing on various theories or frameworks and/or focusing on different components of the goal pursuit process in isolation. Although research on these separate components has served as a necessary foundation for advancing our understanding of goal pursuit, it is helpful to consider this research in the context of a more wholistic model. Having one model that incorporates all stages and aspects of goal pursuit thus allows us to organize the existing literature, as well as provide clear direction for future research. This includes highlighting the need for more research using different methodologies and in different sub-areas of psychology (e.g., organizational psychology, social psychology). For example, meta-analyses can be conducted to summarize research on any of the proposed links (e.g., how lack of progress enhances effort; the effects of personality on goal pursuit). This model also allows researchers to generate testable new hypotheses, particularly regarding boundary conditions. As one example, we proposed that anticipating or experiencing obstacles may lead people to engage in planning behaviours; future research can examine when this is likely to occur. Additional new research questions or hypotheses would also stem from proposed contextual moderators. While much is known about the effects of certain contextual and/or personality influences on certain aspects of goal pursuit (e.g., effects of close others on goal striving; effects of age on goal setting), our model highlights many other areas that remain unexplored. 
In addition to integrating previous theories, our model also proposes some novel theoretical components. First, the existence and especially the nature of the alarm, while consistent with some prior research and theorizing (Inzlicht \& Legault, 2013), has not previously been formally incorporated into theories of goal pursuit, and needs to be closely examined. Future research can disentangle whether and when the alarm is effective, and whether it needs to be consciously experienced (e.g., as a worsening of affect, or a feeling of tension) to engender more effort. Additionally, it may be that some characteristics of the goal itself lead to different thresholds for the alarm for example, the alarm may be more 'sensitive' when a goal is especially important, is more closely tied to an person's identity, or when a person has made a public commitment about their goal. Second, we propose that when goals are re-activated, they can have different characteristics than when the goal was initially set. For example, although a goal may be moderately difficult at first, it may be (perceived as) more or less difficult over time as the person realizes that they have more or less resources to pursue it, or as they get closer to attaining the goal.

Other possible future directions stem from the integration of multiple models and theories into our integrative model of goal pursuit. For example, future research and theorizing can attempt to better integrate the role of affect in the process of self-regulation (drawing from the cybernetic model of self-regulation, Carver \& Scheier, 2000), and especially in better understanding the alarm component. Another future research direction (drawing from the role of planning in the rubicon model, Gollwitzer, 1990) could be to investigate the goal pursuit process in instances when planning is used versus not, focusing not only on effects on progress (e.g., Koestner et al., 2002), but also on the other components of the model (e.g., activation of the alarm; experiences of temptations). Additional theoretical questions that arise from our model concern the pursuit of multiple goals. For example, does the attainment or completion of a goal automatically lead to a return to goal setting/activation (such that a goal is always active)? Finally, within our integrative model of goal pursuit, propositions from some models that specify particular properties of goals as important for goal striving (e.g., specificity and difficulty in goal setting theory, Locke \& Latham, 1990; selfconcordance in self-determination theory, Ryan \& Deci, 2017; approach-avoidance motivation, Eliott, 1999) can also be tested against and in combination with propositions from other models. For example, future research can examine whether specific goals that are also autonomous are especially beneficial, such that both together have additive effects above the effects of autonomy or specificity alone.

Notably, our model is purposefully meant to be broad. Our aim is not to set up a "new" theory that can be supported or rejected, but rather is intended to unify and extend prior theories and findings. Like other models on which our model is based (goal setting theory, self-regulation model, etc.), our model is meant to evolve to accommodate new findings and is a way to organize and drive research forward. Indeed, it specifically acknowledges the role of moderators (e.g., broader contexts), as well as different possible pathways from each component as a way to expand current research, therefore opening new avenues regarding the conditions under which different paths will be taken. Even though we discussed how this model can be integrated with a selection of other theories and models, there are many others that we have not discussed or touched on only briefly (e.g., action control theory, Kuhl, 1992; the multiple-goal pursuit model and its extended version, Ballard et al., 2016; Vancouver et al., 2010; the integrated cybernetic model, Wilkowski \& Ferguson, 2016). Future research and theorizing can more explicitly examine whether and how these theories can fit within one integrative model of goal pursuit.

Although we attempted to review and address most of the aspects of goal pursuit, by necessity some of this review was brief, and other aspects have not been addressed. For example, much more is known about the characteristics of goals than we were able to cover here (see Austin \& Vancouver, 1996, for a review, which is already 25 years old). Some aspects that are likely extremely relevant were only briefly mentioned. For example, how goals are nested within a larger goal hierarchy has been addressed by goal systems theory; we propose ways in which our model can incorporate these ideas (e.g., planning could take the form of making more concrete goals), but a lot more research is needed to examine whether and how this occurs in people's day-to-day lives. Additionally, it is not always clear what occurs when a goal is completed - does a person immediately reset a new goal, and is this new goal in some way related to the recently completed goal (e.g., after I complete this paper, I will turn my attention to another project), or do people use their freed-up resources on completely different goals (e.g., I completed a paper, and now I can relax and watch a movie)? The literature on goal pursuit is broad, with many aspects still unexamined. 
From a practical perspective, an integrative model of goal pursuit can be useful for individuals and those helping them pursue goals (e.g., coaches, supervisors, therapists). By providing a better overview of how the goal pursuit process unfolds, it can help people understand their own goal pursuit and identify where they need to improve to better attain their goals. For example, a person may notice that their goal striving is ineffective, or that they often encounter obstacles - the present model would suggest that planning can be helpful, or that the person is using too much effort and need to develop better habits. An employer could discuss the model with their employees to identify what each step may look like, including what to do in cases of obstacles to ensure they maximize their performance (rather than abandoning a goal). Additionally, once sufficient research is conducted on each step, this model allows for the provision of concrete recommendations for each part - for example, how to set goals that are most likely to be attained? What contextual supports best facilitate the process? Overall, having one integrative model provides a way to organize the information on research findings that is transmitted to knowledge users.

\section{Conclusions}

In this paper, we present an integrative model of goal pursuit that aims to consolidate evidence from a variety of theories and perspectives. The integrative model of goal pursuit addresses all aspects of the goal pursuit process, including goal setting, goal striving, and goal adjustment. Our model also addresses two additional aspects of goal pursuit that have received limited attention in previous formal models, but are nevertheless recognized as important. First, our integrative model of goal pursuit explicitly models contextual and personality influences on goal setting and pursuit, including influences of culture, other people, and the domains in which goal pursuit unfolds. Second, although it is not illustrated in the model, we address how this model can be applied to the dynamics of multiple goal pursuit. In sum, the integrative model of goal pursuit is a comprehensive model that can organize existing literature and provide direction for future research.

\section{References}

Aarts, H., Gollwitzer, P. M., \& Hassin, R. R. (2004). Goal contagion: perceiving is for pursuing. Journal of personality and social psychology, 87(1), 23.
Adriaanse, M. A., Kroese, F. M., Gillebaart, M., \& De Ridder, D. T. (2014). Effortless inhibition: Habit mediates the relation between self-control and unhealthy snack consumption. Frontiers in psychology, 5, 444.

Altmann, E. M., \& Trafton, J. G. (2002). Memory for goals: An activation-based model. Cognitive science, 26(1), 3983.

Anderson, J. R., Bothell, D., Byrne, M. D., Douglass, S., Lebiere, C., \& Qin, Y. (2004). An integrated theory of the mind. Psychological review, 111(4), 1036.

Austin, J. T., \& Vancouver, J. B. (1996). Goal constructs in psychology: Structure, process, and content. Psychological bulletin, 120(3), 338.

Ballard, T., Yeo, G., Loft, S., Vancouver, J. B., \& Neal, A. (2016). An integrative formal model of motivation and decision making: The MGPM*. Journal of Applied Psychology, 101(9), 1240.

Ballard, T., Vancouver, J. B., \& Neal, A. (2018). On the pursuit of multiple goals with different deadlines. Journal of Applied Psychology, 103(11), 1242-1264.

Bandura, A. (1969). Social-learning theory of identificatory processes. Handbook of socialization theory and research, 213, 262.

Bandura, A. (1997). Self-efficacy: The exercise of control. New York, NY: Freeman

Bandura, A. (2018). Toward a psychology of human agency: Pathways and reflections. Perspectives on Psychological Science, 13(2), 130-136.

Beck, J. W., Scholer, A. A., \& Hughes, J. (2017). Divergent effects of distance versus velocity disturbances on emotional experiences during goal pursuit. Journal of Applied Psychology, 102, 1109-1123.

Berkman, E. T., Hutcherson, C. A., Livingston, J. L., Kahn, L. E., \& Inzlicht, M. (2017). Self-control as value-based choice. Current directions in psychological science, 26(5), 422-428.

Berrios, R., Totterdell, P., \& Kellett, S. (2015). Investigating goal conflict as a source of mixed emotions. Cognition and Emotion, 29(4), 755-763.

Bem, D. J. (1972). Self-perception theory. In Advances in experimental social psychology (Vol. 6, pp. 1-62). Academic Press.

Brandtstädter, J., \& Rothermund, K. (2002). The life-course dynamics of goal pursuit and goal adjustment: A twoprocess framework. Developmental review, 22(1), 117 150.

Brandstätter, V., \& Herrmann, M. (2016). Goal disengagement in emerging adulthood: The adaptive potential of action crises. International Journal of Behavioral Development, 40(2), 117-125.

Brandstätter, V., Herrmann, M., \& Schüler, J. (2013). The struggle of giving up personal goals: Affective, physiological, and cognitive consequences of an action crisis. Personality and Social Psychology Bulletin, 39(12), 1668-1682.

Briskin, J. L., Kopetz, C. E., Fitzsimons, G. M., \& Slatcher, R. B. (2019). For better or for worse? Outsourcing self- 
regulation and goal pursuit. Social Psychological and Personality Science, 10(2), 181-192.

Brodscholl, Jeff C., Hedy Kober, and E. Tory Higgins (2007), 7"Strategies of Self-Regulation in Goal Attainment versus Goal Maintenance. European Journal of Social Psychology, 37 (4), 628-48.

Cappuzzello, A. C., \& Gere, J. (2018). Can you make my goals easier to achieve? Effects of partner instrumentality on goal pursuit and relationship satisfaction. Personal Relationships, 25(2), 268-279.

Carbonneau, N., \& Milyavskaya, M. (2017). Your goals or mine? Women's personal and vicarious eating regulation goals and their partners' perceptions of support, wellbeing, and relationship quality. Motivation and Emotion, 41(4), 465-477.

Carr, S., \& Weigand, D. A. (2001). Parental, peer, teacher and sporting hero influence on the goal orientations of children in physical education. European physical education review, 7(3), 305-328.

Carver, C. S. (2015). Control processes, priority management, and affective dynamics. Emotion Review, 7(4), 301-307.

Carver, C. S., \& Scheier, M. F. (1982). Control theory: A useful conceptual framework for personality-social, clinical, and health psychology. Psychological bulletin, 92(1), 111.

Carver, C. S., \& Scheier, M. F. (1990). Origins and functions of positive and negative affect: a control-process view. Psychological review, 97(1), 19.

Carver, C. S., \& Scheier, M. F. (2000). Scaling back goals and recalibration of the affect system are processes in normal adaptive self-regulation: understanding 'response shift' phenomena. Social science \& medicine, 50(12), 1715-1722.

Carver, C. S., \& Scheier, M. F. (2001). On the self-regulation of behavior. Cambridge University Press.

Carver, C. S., Sinclair, S., \& Johnson, S. L. (2010). Authentic and hubristic pride: Differential relations to aspects of goal regulation, affect, and self-control. Journal of research in personality, 44(6), 698-703.

Chartrand, T. L., \& Bargh, J. A. (1996). Automatic activation of impression formation and memorization goals: Nonconscious goal priming reproduces effects of explicit task instructions. Journal of personality and Social Psychology, 71(3), 464.

Chartrand, T. L., \& Bargh, J. A. (2002). Nonconscious motivations: Their activation, operation, and consequences. In A. Tesser, D. A. Stapel, \& J. V. Wood (Eds.), Self and motivation: Emerging psychological perspectives (p. 13-41). American Psychological Association.

Chun, W. Y., Kruglanski, A. W., Sleeth-Keppler, D., \& Friedman, R. S. (2011). Multifinality in implicit choice. Journal of personality and social psychology, 101(5), 1124.

Collins, W. A., Maccoby, E. E., Steinberg, L., Hetherington, E. M., \& Bornstein, M. H. (2000). Contemporary research on parenting: The case for nature and nurture. American psychologist, 55(2), 218.

Corker, K. S., Oswald, F. L., \& Donnellan, M. B. (2012). Conscientiousness in the classroom: A process explanation. Journal of Personality, 80(4), 995-1028.

Covington, M. V. (2000). Goal theory, motivation, and school achievement: An integrative review. Annual review of psychology, 51(1), 171-200.

Csikszentmihalyi, M. (1990). Flow: The psychology of optimal experience. New York: HarperCollins.

Csikszentmihalyi, M., \& Rathunde, K. (1993). The measurement of flow in everyday life: Toward a theory of emergent motivation. In J. E. Jacobs (Ed.), Current theory and research in motivation, Vol. 40. Nebraska Symposium on Motivation, 1992: Developmental perspectives on motivation (p. 57-97). University of Nebraska Press.

Custers, R., \& Aarts, H. (2007). In search of the nonconscious sources of goal pursuit: Accessibility and positive affective valence of the goal state. Journal of Experimental Social Psychology, 43(2), 312-318.

De Ridder, D. T., Lensvelt-Mulders, G., Finkenauer, C., Stok, F. M., \& Baumeister, R. F. (2012). Taking stock of self-control: A meta-analysis of how trait self-control relates to a wide range of behaviors. Personality and Social Psychology Review, 16(1), 76-99.

De Vet, E., Oenema, A., \& Brug, J. (2011). More or better: Do the number and specificity of implementation intentions matter in increasing physical activity?. Psychology of Sport and Exercise, 12(4), 471477.

De Vet, E., Oenema, A., Sheeran, P., \& Brug, J. (2009). Should implementation intentions interventions be implemented in obesity prevention: the impact of if-then plans on daily physical activity in Dutch adults. International journal of behavioral nutrition and physical activity, 6(1), 1-9.

Deci, E. L., \& Ryan, R. M. (2000). The" what" and" why" of goal pursuits: Human needs and the self-determination of behavior. Psychological inquiry, 11(4), 227-268.

Dietrich, J., Shulman, S., \& Nurmi, J. E. (2013). Goal pursuit in young adulthood: The role of personality and motivation in goal appraisal trajectories across 6 years. Journal of Research in Personality, 47(6), 728-737.

Dominick, J. K. (2020). Social self-control: co-indulging impacts post-indulgence emotions and motivation. Retrieved from https://doi.org/doi:10.7282/t3-f98v-3h13

Duckworth, A. L., Grant, H., Loew, B., Oettingen, G., \& Gollwitzer, P. M. (2011). Self-regulation strategies improve self-discipline in adolescents: Benefits of mental contrasting and implementation intentions. Educational Psychology, 31(1), 17-26.

Duckworth, A. L., Kirby, T. A., Gollwitzer, A., \& Oettingen, G. (2013). From fantasy to action: Mental contrasting with implementation intentions (MCII) improves academic performance in children. Social Psychological and Personality Science, 4(6), 745-753. 
Duriez, B., Soenens, B., \& Vansteenkiste, M. (2008). The intergenerational transmission of authoritarianism: The mediating role of parental goal promotion. Journal of Research in Personality, 42(3), 622-642.

Eccles, J. S., Adler, T. F., Futterman, R., Goff, S. B., Kaczala, C. M., Meece, J. L., \& Midgley, C. (1983). Expectancies, values, and academic behaviors. In J. T. Spence (Ed.), Expectancies, values, and academic behaviors (pp. 75146). San Francisco, CA: Freeman.

Eccles, J. S., \& Wigfield, A. (2002). Motivational beliefs, values, and goals. Annual Review of Psychology, 53, 109 -132 .

Elkins-Brown, N., Saunders, B., \& Inzlicht, M. (2016). Error-related electromyographic activity over the corrugator supercilii is associated with neural performance monitoring. Psychophysiology, 53(2), 159-170.

Elliot, A. (1999). Approach and avoidance motivation and achievement goals. Educational Psychologist, 34, 169189.

Elliott, E. S., \& Dweck, C. S. (1988). Goals: An approach to motivation and achievement. Journal of personality and social psychology, 54(1), 5.

Elliot, A. J., \& Fryer, J. W. (2008). The goal construct in psychology. Handbook of motivation science, 18, 235-250.

Emmons, R. A. (1986). Personal strivings: An approach to personality and subjective well-being. Journal of Personality and Social Psychology, 51, 1058-1068.

Epton, T., Currie, S., \& Armitage, C. J. (2017). Unique effects of setting goals on behavior change: Systematic review and meta-analysis. Journal of consulting and clinical psychology, 85(12), 1182.

Fazio, R. H. (1987). Self-perception theory: A current perspective. In Social influence: the Ontario symposium (Vol. 5, pp. 129-150).

Fishbach, A., Eyal, T., \& Finkelstein, S. R. (2010). How positive and negative feedback motivate goal pursuit. Social and Personality Psychology Compass, 4(8), 517-530.

Fishbach, A., Friedman, R. S., \& Kruglanski, A. W. (2003). Leading us not into temptation: Momentary allurements elicit overriding goal activation. Journal of personality and social psychology, 84(2), 296.

Fitzsimons, G. M., Finkel, E. J., \& Vandellen, M. R. (2015). Transactive goal dynamics. Psychological Review, 122(4), 648.

Forster, J., Liberman, N., \& Higgins, E. T. (2005). Accessibility from active and fulfilled goals. Journal of Experimental Social Psychology, 41, 220-239.

Freitas, A. L., Liberman, N., Salovey, P., \& Higgins, E. T. (2002). When to begin? Regulatory focus and initiating goal pursuit. Personality and Social Psychology Bulletin, 28(1), 121-130.

Freund, A. M., \& Riediger, M. (2006). Goals as building blocks of personality and development in adulthood. In Handbook of personality development (pp. p-353). Erlbaum.
Fujita, K. (2011). On conceptualizing self-control as more than the effortful inhibition of impulses. Personality and social psychology review, 15(4), 352-366.

Galla, B. M., \& Duckworth, A. L. (2015). More than resisting temptation: Beneficial habits mediate the relationship between self-control and positive life outcomes. Journal of personality and social psychology, 109(3), 508.

Geldhof, G. J., Little, T. D., \& Colombo, J. (2010). Selfregulation across the life span. The Handbook of Life-Span Development.

Gendolla, G. H., \& Richter, M. (2010). Effort mobilization when the self is involved: Some lessons from the cardiovascular system. Review of general psychology, 14(3), 212-226.

Gendolla, G. H., \& Wright, R. A. (2009). Effort. The Oxford companion to emotion and the affective sciences, 134-135.

Gere, J., \& Impett, E. A. (2018). Shifting priorities: Effects of partners' goal conflict on goal adjustment processes and relationship quality in developing romantic relationships. Journal of Social and Personal Relationships, 35(6), 793-810.

Ghassemi, M., Bernecker, K., Herrmann, M., \& Brandstätter, V. (2017). The process of disengagement from personal goals: reciprocal influences between the experience of action crisis and appraisals of goal desirability and attainability. Personality and Social Psychology Bulletin, 43(4), 524-537.

Gillebaart, M., \& de Ridder, D. T. (2015). Effortless selfcontrol: A novel perspective on response conflict strategies in trait self-control. Social and Personality Psychology Compass, 9(2), 88-99.

Girme, Y. U., Overall, N. C., \& Simpson, J. A. (2013). When visibility matters: Short-term versus long-term costs and benefits of visible and invisible support. Personality and social psychology bulletin, 39(11), 1441-1454.

Gollwitzer, P. M. (1990). Action phases and mindsets. Handbook of motivation and cognition: Foundations of social behavior, 2, 53-92.

Gollwitzer, P. M. (1999). Implementation intentions: strong effects of simple plans. American psychologist, 54(7), 493.

Gollwitzer, P. M., \& Sheeran, P. (2006). Implementation intentions and goal achievement: A meta-analysis of effects and processes. Advances in experimental social psychology, 38, 69-119.

Gore, J. S. (2014). The influence of close others in daily goal pursuit. Journal of Social and Personal Relationships, 31(1), 71-92.

Gore, J. S., Cross, S. E., \& Kanagawa, C. (2009). Acting in our interests: Relational self-construal and goal motivation across cultures. Motivation and Emotion, 33(1), 75-87.

Goschke, T., \& Dreisbach, G. (2008). Conflict-triggered goal shielding: Response conflicts attenuate background monitoring for prospective memory cues. Psychological Science, 19, 25-32

Grolnick, W. S., Deci, E. L., \& Ryan, R. M. (1997). Internalization within the family: The self-determination theory perspective. In J.E. Grusec,(Ed.). Parenting and 
children's internalization of values: A handbook of contemporary theory, 135-161.

Grund, A., \& Fries, S. (2018). Understanding procrastination: A motivational approach. Personality and Individual Differences, 121, 120-130.

Grusec, J. E., \& Davidov, M. (2010). Integrating different perspectives on socialization theory and research: A domain-specific approach. Child development, 81(3), 687709.

Guinote, A. (2007). Power and goal pursuit. Personality and Social Psychology Bulletin, 33(8), 1076-1087.

Hajcak, G., \& Foti, D. (2008). Errors are aversive: Defensive motivation and the error-related negativity. Psychological science, 19(2), 103-108.

Hannafin, M. J. (1981). Effects of teacher and student goal setting and evaluations on mathematics achievement and student attitudes. The Journal of Educational Research, 74(5), 321-326.

Harkin, B., Webb, T. L., Chang, B. P., Prestwich, A., Conner, M., Kellar, I., ... \& Sheeran, P. (2016). Does monitoring goal progress promote goal attainment? A meta-analysis of the experimental evidence. Psychological bulletin, 142(2), 198.

Heckhausen, H., \& Gollwitzer, P. M. (1987). Thought contents and cognitive functioning in motivational versus volitional states of mind. Motivation and emotion, 11(2), 101-120.

Higgins, E. T. (1997). Beyond pleasure and pain. American psychologist, 52(12), 1280.

Hofmann, W., Baumeister, R. F., Förster, G., \& Vohs, K. D. (2012). Everyday temptations: an experience sampling study of desire, conflict, and self-control. Journal of personality and social psychology, 102(6), 1318.

Holding, A. C., Hope, N. H., Harvey, B., Marion Jetten, A. S., \& Koestner, R. (2017). Stuck in limbo: Motivational antecedents and consequences of experiencing action crises in personal goal pursuit. Journal of Personality, 85, 893-905.

Huang, S.-c., Lin, S. C., \& Zhang, Y. (2019). When individual goal pursuit turns competitive: How we sabotage and coast. Journal of Personality and Social Psychology, 117(3), 605-620.

Ilies, R., \& Judge, T. A. (2005). Goal regulation across time: the effects of feedback and affect. Journal of applied psychology, 90(3), 453.

Inzlicht, M., \& Legault, L. (2014). No pain, no gain: How distress underlies effective self-control (and unites diverse social psychological phenomena). In J. P. Forgas \& E. Harmon-Jones (Eds.), Sydney symposium of social psychology. Motivation and its regulation: The control within (p. 115-132). Psychology Press.

Inzlicht, M., Shenhav, A., \& Olivola, C. Y. (2018). The effort paradox: Effort is both costly and valued. Trends in cognitive sciences, 22(4), 337-349.

Inzlicht, M., Werner, K. M., Briskin, J. L., \& Roberts, B. W. (2021). Integrating models of self-regulation. Annual review of psychology, 72, 319-345.
Joussemet, M., Koestner, R., Lekes, N., \& Landry, R. (2005). A longitudinal study of the relationship of maternal autonomy support to children's adjustment and achievement in school. Journal of personality, 73(5), 1215-1236.

Joussemet, M., Mageau, G. A.Larose, M.-P.Briand, M. (2018) How to talk so kids will listen \& listen so kids will talk: a randomized controlled trial evaluating the efficacy of the French How-to Parenting Program on children's mental health compared to a wait-list control group. $B M C$ Pediatrics, 18(1), 257

Joussemet, M., Mageau, G. A., Koestner, R. (2014) Promoting optimal parenting and children's mental health: A preliminary evaluation of the how-to parenting program. Journal of Child and Family Studies, 23 ,949-964

Judge, T. A., \& Ilies, R. (2002). Relationship of personality to performance motivation: A meta-analytic review. Journal of applied psychology, 87(4), 797.

Karoly, P. (1999). A goal systems-self-regulatory perspective on personality, psychopathology, and change. Review of General Psychology, 3(4), 264-291.

Karreman, A., Van Tuijl, C., van Aken, M. A., \& Deković, M. (2006). Parenting and self-regulation in preschoolers: A meta-analysis. Infant and Child Development: An International Journal of Research and Practice, 15(6), 561-579.

Kasser, T., \& Ryan, R. M. (1996). Further examining the American dream: Differential correlates of intrinsic and extrinsic goals. Personality and social psychology bulletin, 22(3), 280-287.

Keegan, R., Spray, C., Harwood, C., \& Lavallee, D. (2010). The motivational atmosphere in youth sport: Coach, parent, and peer influences on motivation in specializing sport participants. Journal of applied sport psychology, 22(1), 87-105.

Kerns, J. G., Cohen, J. D., MacDonald, A. W., Cho, R. Y., Stenger, V. A., \& Carter, C. S. (2004). Anterior cingulate conflict monitoring and adjustments in control. Science, 303(5660), 1023-1026.

Klein, H. J., Wesson, M. J., Hollenbeck, J. R., \& Alge, B. J. (1999). Goal commitment and the goal-setting process: conceptual clarification and empirical synthesis. Journal of applied psychology, 84(6), 885.

Klinger, E., \& Cox, W. M. (2004). Motivation and the Theory of Current Concerns. In W. M. Cox \& E. Klinger (Eds.), Handbook of motivational counseling: Concepts, approaches, and assessment (p. 3-27). John Wiley \& Sons Ltd.

Knäuper, B., Shireen, H., Carrière, K., Frayn, M., Ivanova, E., Xu, Z., ... \& Grover, S. (2020). The effects of if-then plans on weight loss: results of the 24-month follow-up of the McGill CHIP Healthy Weight Program randomized controlled trial. Trials, 2l(1), 1-7.

Koch, I., Poljac, E., Müller, H., \& Kiesel, A. (2018). Cognitive structure, flexibility, and plasticity in human multitasking-An integrative review of dual-task and 
task-switching research. Psychological Bulletin, 144(6), 557-583.

Kochanska, G. (2002). Committed compliance, moral self, and internalization: A mediational model. Developmental Psychology, 38(3), 339-351

Koestner, R., Lekes, N., Powers, T. A., \& Chicoine, E. (2002). Attaining personal goals: Self-concordance plus implementation intentions equals success. Journal of personality and social psychology, 83(1), 231.

Koestner, R., Otis, N., Powers, T. A., Pelletier, L., \& Gagnon, H. (2008). Autonomous motivation, controlled motivation, and goal progress. Journal of personality, 76(5), 1201-1230.

Koestner, R., Powers, T. A., Carbonneau, N., Milyavskaya, M., \& Chua, S. N. (2012). Distinguishing autonomous and directive forms of goal support: Their effects on goal progress, relationship quality, and subjective wellbeing. Personality and Social Psychology Bulletin, 38(12), 1609-1620.

Koestner, R., Powers, T. A., Milyavskaya, M., Carbonneau, N., \& Hope, N. (2015). Goal internalization and persistence as a function of autonomous and directive forms of goal support. Journal of Personality, 83(2), 179-190.

Köpetz, C., Faber, T., Fishbach, A., \& Kruglanski, A. W. (2011). The multifinality constraints effect: How goal multiplicity narrows the means set to a focal end. Journal of Personality and Social Psychology, 100, 810-826

Kotabe, H. P., \& Hofmann, W. (2015). On integrating the components of self-control. Perspectives on Psychological Science, 10(5), 618-638.

Kozlowski, S. W., \& Bell, B. S. (2006). Disentangling achievement orientation and goal setting: Effects on selfregulatory processes. Journal of Applied Psychology, 91(4), 900.

Kruglanski, A. W. (1996). Goals as knowledge structures. In P. M. Gollwitzer \& J. A. Bargh (Eds.), The psychology of action: Linking cognition and motivation to behavior ( $\mathrm{p}$. 599-618). The Guilford Press.

Kruglanski, A. W., Chernikova, M., Babush, M., Dugas, M., \& Schumpe, B. M. (2015). The architecture of goal systems: Multifinality, equifinality, and counterfinality in means - end relations. In Advances in motivation science (Vol. 2, pp. 69-98). Elsevier.

Kruglanski, A. W., Orehek, E., Higgins, E. T., Pierro, A., \& Shalev, I. (2009). Assessment and locomotion as independent determinants in goal pursuit. Handbook of personality and self-regulation, 375-402.

Kruglanski, A. W., Shah, J. Y., Fishbach, A., Friedman, R., Chun, W. Y., \& Sleeth-Keppler, D. (2002). A theory of goal systems. In Advances in Experimental Social Psychology (Vol. 34, pp. 331-378). Academic Press.

Kuhl, J. (1992). A theory of self-regulation: Action versus state orientation, self-discrimination, and some applications. Applied Psychology, 41(2), 97-129.
Kung, F. Y., \& Scholer, A. A. (2020). The pursuit of multiple goals. Social and Personality Psychology Compass, 14(1), e12509.

Larzelere, R. E., Morris, A. S. E., \& Harrist, A. W. (2013). Authoritative parenting: Synthesizing nurturance and discipline for optimal child development. American Psychological Association.

Laurin, J. C., \& Joussemet, M. (2017). Parental autonomysupportive practices and toddlers' rule internalization: A prospective observational study. Motivation and Emotion, 41(5), 562-575.

Laurin, K., Fitzsimons, G. M., Finkel, E. J., Carswell, K. L., vanDellen, M. R., Hofmann, W., Lambert, N. M., Eastwick, P. W., Fincham, F. D., \& Brown, P. C. (2016). Power and the pursuit of a partner's goals. Journal of Personality and Social Psychology, 110(6), 840-868.

Lawrence, J. W., Carver, C. S., \& Scheier, M. F. (2002). Velocity toward goal attainment in immediate experience as a determinant of affect. Journal of Applied Social Psychology, 32, 788-802.

Lewin, K., Dembo, T., Festinger, L., \& Sears, P. S. (1944). Level of aspiration.

Little, B. R. (1983). Personal projects: A rationale and method for investigation. Environment and behavior, 15(3), 273-309.

Little, B. R. (2020). How are you doing, really? Personal project pursuit and human flourishing. Canadian Psychology/Psychologie canadienne, 61(2), 140-150.

Little, B. R., Leccl, L., \& Watkinson, B. (1992). Personality and personal projects: Linking Big Five and PAC units of analysis. Journal of personality, 60(2), 501-525.

Locke, E. A., \& Latham, G. P. (1990). A theory of goal setting \& task performance. Prentice-Hall, Inc.

Locke, E. A., \& Latham, G. P. (2006). New directions in goal-setting theory. Current directions in psychological science, 15(5), 265-268.

Locke, E. A., Latham, G. P., \& Erez, M. (1988). The determinants of goal commitment. Academy of management review, 13(1), 23-39.

Lockwood, P., Jordan, C. H., \& Kunda, Z. (2002). Motivation by positive or negative role models: regulatory focus determines who will best inspire us. Journal of personality and social psychology, 83(4), 854.

Louro, M. J., Pieters, R., \& Zeelenberg, M. (2007). Dynamics of multiple-goal pursuit. Journal of personality and social psychology, 93(2), 174.

Marcora, S. (2009). Perception of effort during exercise is independent of afferent feedback from skeletal muscles, heart, and lungs. J. Appl. Physiol. 106, 2060-2062. doi: 10.1152/japplphysiol.90378.2008

Marguc, J., Förster, J., \& Van Kleef, G. A. (2011). Stepping back to see the big picture: When obstacles elicit global processing. Journal of personality and social psychology, 101(5), 883.

Marien, H., Custers, R., Hassin, R. R., \& Aarts, H. (2012). Unconscious goal activation and the hijacking of the 
executive function. Journal of personality and social psychology, 103(3), 399.

McAdams, D. P. (1996). Personality, Modernity, and the Storied Self: A Contemporary Framework for Studying Persons, Psychological Inquiry, 7:4, 295-321.

McAdams, D. P. (2013). The psychological self as actor, agent, and author. Perspectives on Psychological Science, 8(3), 272-295.

McAdams, D. P., \& Pals, J. L. (2006). A new Big Five: fundamental principles for an integrative science of personality. American psychologist, 61(3), 204.

McCabe, K. O., \& Fleeson, W. (2016). Are traits useful? Explaining trait manifestations as tools in the pursuit of goals. Journal of personality and social psychology, 110(2), 287.

McCrae, R. R., \& Costa, P. T., Jr. (1999). A Five-Factor theory of personality. In L. Pervin \& O. John (Eds.), Handbook of personality: Theory and research (pp. 139-153). New York: Guilford Press.

McWilliams, L., Bellhouse, S., Yorke, J., Lloyd, K., \& Armitage, C. J. (2019). Beyond "planning": A metaanalysis of implementation intentions to support smoking cessation. Health Psychology, 38(12), 1059.

Meece, J. L., Anderman, E. M., \& Anderman, L. H. (2006). Classroom goal structure, student motivation, and academic achievement. Annu. Rev. Psychol., 57, 487-503.

Miller, G. A., Galanter, E., \& Pribram, K. H. (1960). Plans and the structure of behavior. New York: Holt, Rinehart \& Winston.

Milyavskaya, M., Berkman, E. T., \& De Ridder, D. T. (2019). The many faces of self-control: Tacit assumptions and recommendations to deal with them. Motivation Science, 5(1), 79.

Milyavskaya, M., Ianakieva, I., Foxen-Craft, E., Colantuoni, A., \& Koestner, R. (2012). Inspired to get there: The effects of trait and goal inspiration on goal progress. Personality and Individual Differences, 52(1), 56-60.

Milyavskaya, M., \& Inzlicht, M. (2017). What's so great about self-control? Examining the importance of effortful self-control and temptation in predicting real-life depletion and goal attainment. Social Psychological and Personality Science, 8(6), 603-611.

Milyavskaya, M., Inzlicht, M., Hope, N., \& Koestner, R. (2015). Saying "no" to temptation: Want-to motivation improves self-regulation by reducing temptation rather than by increasing self-control. Journal of Personality and Social Psychology, 109(4), 677.

Milyavskaya, M., \& Nadolny, D. (2018). Health goals among American adults: Prevalence, characteristics, and barriers. Journal of health psychology, 23(10), 1350-1355.

Milyavskaya, M., Nadolny, D., \& Koestner, R. (2014). Where do self-concordant goals come from? The role of domain-specific psychological need satisfaction. Personality and Social Psychology Bulletin, 40(6), 700-711.
Milyavskaya, M., \& Werner, K. M. (2018). Goal pursuit: Current state of affairs and directions for future research. Canadian Psychology/psychologie canadienne, 59(2), 163.

Monzani, D., Steca, P., Greco, A., D’Addario, M., Pancani, L., \& Cappelletti, E. (2015). Effective pursuit of personal goals: The fostering effect of dispositional optimism on goal commitment and goal progress. Personality and Individual Differences, 82, 203-214.

Moskowitz, G. B., \& Gesundheit, Y. (2009). Goal priming. In G.B. Moskowitz \& H. Grant (Eds.). The psychology of goals. Guilford Press.

Myrseth, K. O. R., \& Fishbach, A. (2009). Self-control: A function of knowing when and how to exercise restraint. Current Directions in Psychological Science, 18(4), 247-252.

Neal, A., Ballard, T., \& Vancouver, J. B. (2017). Dynamic self-regulation and multiple-goal pursuit. Annual Review of Organizational Psychology and Organizational Behavior, 4, 401-423.

Nielsen, K. S., \& Bauer, J. M. (2019). The merits of goal support as a self-control strategy. Social Psychological and Personality Science, 10(5), 671-680.

Niemiec, C. P., \& Ryan, R. M. (2009). Autonomy, competence, and relatedness in the classroom: Applying self-determination theory to educational practice. Theory and research in Education, 7(2), 133-144.

Nurmi, J. E. (1992). Age differences in adult life goals, concerns, and their temporal extension: A life course approach to future-oriented motivation. International Journal of Behavioral Development, 15(4), 487-508.

Nurmi, J.-E., Salmela-Aro, K., \& Aunola, K. (2009). Personal goal appraisals vary across both individuals and goal contents. Personality and Individual Differences, 47, 498-503.

Oettingen, G. (1996). Positive fantasy and motivation. In P. M. Gollwitzer \& J. A. Bargh (Eds.), The psychology of action: Linking cognition and motivation to behavior ( $\mathrm{p}$. 236-259). The Guilford Press.

Oettingen, G. (1999). Free fantasies about the future and the emergence of developmental goals. Action and selfdevelopment: Theory and research through the life span, 315-342.

Oettingen, G., \& Gollwitzer, P. M. (2010). Strategies of setting and implementing goals: Mental contrasting and implementation intentions. In J. E. Maddux \& J. P. Tangney (Eds.), Social psychological foundations of clinical psychology (p. 114-135). The Guilford Press.

Oettingen, G., Kappes, H. B., Guttenberg, K. B., \& Gollwitzer, P. M. (2015). Self-regulation of time management: Mental contrasting with implementation intentions. European Journal of Social Psychology, 45(2), 218-229.

Oettingen, G., Sevincer, A. T., \& Gollwitzer, P. M. (2008). Goal pursuit in the context of culture. In R. Sorrentino, \& S. Yamaguchi (Eds.), The handbook of motivation and 
cognition across cultures (pp. 191-211). San Diego: Elsevier/Academic Press.

Oishi, S., \& Diener, E. (2001). Goals, Culture, and Subjective Well-Being. Personality and Social Psychology Bulletin, 27(12), 1674-1682.

Orehek, E., Bessarabova, E., Chen, X., \& Kruglanski, A. W. (2011). Positive affect as informational feedback in goal pursuit. Motivation and Emotion, 35(1), 44-51.

Orehek, E., \& Vazeou-Nieuwenhuis, A. (2013). Sequential and concurrent strategies of multiple goal pursuit. Review of General Psychology, 17(3), 339-349.

Papies, E. K., \& Hamstra, P. (2010). Goal priming and eating behavior: enhancing self-regulation by environmental cues. Health psychology, 29(4), 384-388.

Powers, W. T. (1973). Feedback: Beyond Behaviorism: Stimulus-response laws are wholly predictable within a control-system model of behavioral organization. Science, 179(4071), 351-356.

Powers, T. A., Koestner, R., \& Gorin, A. A. (2008). Autonomy support from family and friends and weight loss in college women. Families, Systems, \& Health, 26(4), 404.

Powers, T. A., Koestner, R., Zuroff, D. C., Milyavskaya, M., \& Gorin, A. A. (2011). The effects of self-criticism and self-oriented perfectionism on goal pursuit. Personality and Social Psychology Bulletin, 37(7), 964-975.

Presseau, J., Tait, R. I., Johnston, D. W., Francis, J. J., \& Sniehotta, F. F. (2013). Goal conflict and goal facilitation as predictors of daily accelerometer-assessed physical activity. Health Psychology, 32(12), 1179.

Riediger, M., \& Freund, A. M. (2004). Interference and facilitation among personal goals: Differential associations with subjective well-being and persistent goal pursuit. Personality and Social Psychology Bulletin, 30(12), 1511-1523.

Riediger, M., Freund, A. M., \& Baltes, P. B. (2005). Managing life through personal goals: Intergoal facilitation and intensity of goal pursuit in younger and older adulthood. The Journals of Gerontology Series B: Psychological Sciences and Social Sciences, 60(2), P84P91.

Roberts, B. W., \& Robins, R. W. (2000). Broad dispositions, broad aspirations: The intersection of personality traits and major life goals. Personality and Social Psychology Bulletin, 26(10), 1284-1296.

Ryan, R. M., \& Deci, E. L. (2017). Self-determination theory: Basic psychological needs in motivation, development, and wellness. Guilford Publications.

Ryan, R. M., \& Deci, E. L. (2020). Intrinsic and extrinsic motivation from a self-determination theory perspective: Definitions, theory, practices, and future directions. Contemporary Educational Psychology, 61, 101860.

Saunders, B., Milyavskaya, M., \& Inzlicht, M. (2015). What does cognitive control feel like? Effective and ineffective cognitive control is associated with divergent phenomenology. Psychophysiology, 52(9), 1205-1217.
Schmeichel, B. J., \& Inzlicht, M. (2013). Incidental and integral effects of emotions on self-control. In M. D. Robinson, E. Watkins, \& E. Harmon-Jones (Eds.), Handbook of cognition and emotion (p. 272-290). The Guilford Press.

Seijts, G. H., Latham, G. P., Tasa, K., \& Latham, B. W. (2004). Goal setting and goal orientation: An integration of two different yet related literatures. Academy of management journal, 47(2), 227-239.

Shah, J. Y., Friedman, R., \& Kruglanski, A. W. (2002). Forgetting all else: on the antecedents and consequences of goal shielding. Journal of personality and social psychology, 83(6), 1261.

Shah, J. Y. (2005). The automatic pursuit and management of goals. Current Directions in Psychological Science, 14(1), 10-13.

Sheldon, K. M., \& Elliot, A. J. (1998). Not all personal goals are personal: Comparing autonomous and controlled reasons for goals as predictors of effort and attainment. Personality and Social Psychology Bulletin, 24(5), 546-557.

Sheldon, K. M., \& Elliot, A. J. (1999). Goal striving, need satisfaction, and longitudinal well-being: the selfconcordance model. Journal of personality and social psychology, 76(3), 482.

Sheldon, K. M., \& Elliot, A. J. (2000). Personal goals in social roles: Divergences and convergences across roles and levels of analysis. Journal of Personality, 68(1), 5184.

Sheldon, K. M., Elliot, A. J., Ryan, R. M., Chirkov, V., Kim, Y., Wu, C., ... \& Sun, Z. (2004). Self-concordance and subjective well-being in four cultures. Journal of crosscultural psychology, 35(2), 209-223.

Sheldon, K. M., \& Kasser, T. (2001). Getting older, getting better? Personal strivings and psychological maturity across the life span. Developmental psychology, 37(4), 491.

Smyth, A. P., Werner, K. M., Milyavskaya, M., Holding, A., \& Koestner, R. (2020). Do mindful people set better goals? Investigating the relation between trait mindfulness, selfconcordance, and goal progress. Journal of Research in Personality, 88, 104015.

Soenens, B., Vansteenkiste, M., Lens, W., Luyckx, K., Goossens, L., Beyers, W., \& Ryan, R. M. (2007). Conceptualizing parental autonomy support: Adolescent perceptions of promotion of independence versus promotion of volitional functioning. Developmental psychology, 43(3), 633.

Spera, C. (2005). A review of the relationship among parenting practices, parenting styles, and adolescent school achievement. Educational psychology review, 17(2), 125146.

Stanek, J. C., \& Richter, M. (2021). Energy investment and motivation: The additive impact of task demand and reward value on exerted force in hand grip tasks. Motivation and Emotion, 1-15. 
Steele, J. (2020, June 6). What is (perception of) effort? Objective and subjective effort during task performance. https://doi.org/10.31234/osf.io/kbyhm

Takarada, Y., \& Nozaki, D. (2018). Motivational goalpriming with or without awareness produces faster and stronger force exertion. Scientific reports, 8(1), 1-12.

Tardy, C. (1985). Social support measurement. American Journal of Community Psychology, 13, 187-202.

Thomas, R. M., \& Schnitker, S. A. (2017). Modeling the effects of within-person characteristic and goal-level attributes on personal project pursuit over time. Journal of Research in Personality, 69, 206-217.

Thürmer, J. L., Scheier, M. F., \& Carver, C. S. (2020). On the mechanics of goal striving: Experimental evidence of coasting and shifting. Motivation Science, 6(3), 266-274.

Toli, A., Webb, T. L., \& Hardy, G. E. (2016). Does forming implementation intentions help people with mental health problems to achieve goals? A meta-analysis of experimental studies with clinical and analogue samples. British Journal of Clinical Psychology, 55(1), 6990.

Tolli, A. P., \& Schmidt, A. M. (2008). The role of feedback, causal attributions, and self-efficacy in goal revision. Journal of Applied Psychology, 93(3), 692-701.

Triandis, H. C. (1995). Individualism \& collectivism. Boulder, CO: Western Press.

vanDellen, M. R., Shah, J. Y., Leander, N. P., Delose, J. E., \& Bornstein, J. X. (2015). In good company managing interpersonal resources that support self-regulation. Personality and Social Psychology Bulletin, 41, 869-882

Vasquez, A. C., Patall, E. A.Fong, C. J.Corrigan, A. S.Pine, L. (2016) . Parent autonomy support, academic achievement, and psychosocial functioning: A metaanalysis of research. Educational Psychology Review, $28(3), 605-644$

Vaughn, L. A. (2017). Foundational tests of the need-support model: A framework for bridging regulatory focus theory and self-determination theory. Personality and Social Psychology Bulletin, 43(3), 313-328.

Vowels, L. M., \& K.B., C. (2020, September 27). Partner Support and Goal Pursuit: A Meta-analysis. https://doi.org/10.31234/osf.io/rjwat

Wang, C., \& Mukhopadhyay, A. (2012). The dynamics of goal revision: A cybernetic multiperiod Test-Operate-TestAdjust-Loop (TOTAL) model of self-regulation. Journal of Consumer Research, 38(5), 815-832.

Wentzel, K. R. (1994). Relations of social goal pursuit to social acceptance, classroom behavior, and perceived social support. Journal of Educational Psychology, 86(2), 173-182.
Wentzel, K. R., Baker, S. A., \& Russell, S. L. (2012). Young adolescents' perceptions of teachers' and peers' goals as predictors of social and academic goal pursuit. Applied Psychology, 61(4), 605-633.

Werner, K. M., Milyavskaya, M., Foxen-Craft, E., \& Koestner, R. (2016). Some goals just feel easier: Selfconcordance leads to goal progress through subjective ease, not effort. Personality and Individual Differences, 96, 237-242.

Werner, K. M., Milyavskaya, M., \& Koestner, R. (2018, August 8). Examining the role of approach-avoidance and autonomous-controlled motivation in predicting goal progress over time. https://doi.org/10.31234/osf.io/bs28w

Werner, K. M., Sjåstad, H., Milyavskaya, M., \& Hofmann, W. (2020, July 1). Planning for success: Trait self-control predicts goal attainment through the use of implementation intentions. https://doi.org/10.31234/osf.io/m9u4e

Wilkowski, B. M., \& Ferguson, E. L. (2016). The steps that can take us miles: Examining the short-term dynamics of long-term daily goal pursuit. Journal of Experimental Psychology: General, 145(4), 516.

Wood, W., \& Neal, D. T. (2007). A new look at habits and the habit-goal interface. Psychological review, 114(4), 843.

Wrosch, C., Scheier, M. F., Carver, C. S., \& Schulz, R. (2003). The importance of goal disengagement in adaptive self-regulation: When giving up is beneficial. Self and identity, 2(1), 1-20.

Wrosch, C., Scheier, M. F., Miller, G. E., Schulz, R., \& Carver, C. S. (2003). Adaptive self-regulation of unattainable goals: Goal disengagement, goal reengagement, and subjective well-being. Personality and social psychology bulletin, 29(12), 1494-1508.

Yeung, N., Botvinick, M. M., \& Cohen, J. D. (2004). The neural basis of error detection: conflict monitoring and the error-related negativity. Psychological Review, 111, 931.

Zhang, Y., Fishbach, A., \& Kruglanski, A. W. (2007). The dilution model: How additional goals undermine the perceived instrumentality of a shared path. Journal of personality and social psychology, 92(3), 389.

Zhang, Y., Haddad, E., Torres, B., \& Chen, C. (2011). The reciprocal relationships among parents' expectations, adolescents' expectations, and adolescents' achievement: A two-wave longitudinal analysis of the NELS data. Journal of youth and adolescence, 40(4), 479-489.

This pre-print was designed using the following template: Wiernik, B. M. (2019, October 11). Preprint templates. https://doi.org/10.17605/OSF.IO/HSV6A 